\title{
Limits and developments in ecofriendly corrosion inhibitors of mild steel: a critical review. Part 1: Coumarins
}

\author{
A.A. Al-Amiery, ${ }^{1,2}{ }^{1} *$ A. Kadhim, ${ }^{1}$ A. Al-Adili ${ }^{1}$ and Z.H. Tawfiq ${ }^{3}$ \\ ${ }^{1}$ University of Technology, Baghdad 10001, Iraq \\ ${ }^{2}$ Department of Chemical \& Process Engineering, Faculty of Engineering \& Built \\ Environment, Universiti Kebangsaan Malaysia, Bangi, Selangor, 43600, Malaysia \\ ${ }^{3}$ Al-Esraa University College, Baghdad 10001, Iraq \\ *E-mail: dr.ahmed1975@ukm.edu.my
}

\begin{abstract}
This review summarizes the possibility of using coumarin-derived organic compounds as green environmentally friendly corrosion inhibitors for mild steel alloys in hydrochloric acid environments. These corrosion inhibitors are usually synthesized from coumarin as a basic unit, usually substituted by heterocyclics, double and/or triple bonds, and various other functional groups such as amine, hydroxy and sulfur groups. Due to the presence of multiple functional groups and heterogeneous atoms, coumarins are readily adsorbed as eco-friendly organic compounds on the surface of mild steel alloys, which effectively reduces the degradation of mild steel. In the current review article, the literature based on the inhibition of corrosion of steels by green coumarin-derived inhibitors was evaluated, and the significant results and performance of these inhibitors in acid solutions were confirmed. The application and role of theoretical studies, especially the density function theory (DFT), in predicting the inhibition efficiency of the utilized green inhibitors, as well as the roles and effects of substitution groups in coumarin rings in raising the inhibition efficiency and reducing the corrosion rate were discussed. In addition, the literature dealing with understanding the role of coumarins as anticorrosive materials by codifying the potential mechanism of corrosion inhibition is covered. Coumarins were chosen for this review as they are natural materials in origin, which makes them suitable environmentally friendly candidates as corrosion inhibitors for mild steels.
\end{abstract}

Received: February 18, 2021. Published: September 27, 2021 doi: 10.17675/2305-6894-2021-10-4-1

Keywords: coumarins, corrosion inhibitors, DFT, mild steel.

\section{Introduction}

Hydrochloric acid $(\mathrm{HCl})$ is one of the significant mineral acids that is widely used in many applications, including well acidification, water treatment, chemical cleaning, and acid pickling [1-8]. It takes extreme care and detailed engineering to select cost-effective materials to handle this acid. The presence in the acid and/or high aeration, certain impurities, such as ferric salts, cupric salts, and chlorine, amplifies the oxidizing power of the solution, leading to accelerated damage due to corrosion [9]. Exposure of materials to acid environments is more common and frequent in the oil and gas industry than in neutral 
or alkaline environments [10-13]. This requires exploring the options and effective methods for mitigating and controlling the corrosion of various steel types as they constitute a large fraction of metallic materials exposed to acid media. Mild steel is often used as a construction material in industries, and when exposed to aggressive environments, it is vulnerable to corrosion attacks. In order to protect metals from corrosion, organic corrosion inhibitors from plant extracts have proven to be effective, safe, and economical [14, 15]. When applied, synthetic organic corrosion inhibitors can sometimes be hazardous because of their toxicity to the health and the environment. As alternative sources of corrosion inhibitors, numerous researchers have explored organic inhibitors from natural products. In their functional group, the phytochemical constituents present in these natural materials have been found to have unique electronic structures with lone electron pairs on their heteroatoms $(\mathrm{O}, \mathrm{N}, \mathrm{S}$, etc. $), \pi$ bonds, or triple bonds that are known attributes of good corrosion inhibitors. Indeed, plant materials such as leaves, bark, and plant fruits have been shown to be excellent corrosion inhibitors [15-17]. Corrosion mitigation approaches adopted in some sectors include, among others, the selection of materials, coatings and linings, cathodic protection, and the use of corrosion inhibitors. The use of corrosion inhibitors is the most practical and cost-effective method for combating corrosion. Corrosion inhibitors retard corrosion by adsorbing and blocking one or more of the electrochemical reactions occurring at the solution/metal interface on a low carbon steel surface. Organic compounds, including imidazolines, amides, amines, and their derived salts, are well-known corrosion inhibitors [18]. The structures of these organic compounds typically contain nitrogen, sulfur and oxygen, and hydrophobic hydrocarbon chains. However, inhibitors are usually effective in a certain environment only for a specific material [19], but the corrosion environment is highly variable; therefore, an inhibitor working in one well may not work in another [20]. Therefore, new formulas for different environments need to be continually developed [21] and numerous compounds have been designed [22]. Organic compounds alone are also generally not sufficiently effective and a proper blend containing additional intensifiers, surfactants, and solvents is required [23]. Functional groups in organic molecules impart corrosion inhibition [24]. Coumarin was first isolated by A. Vogel in 1820 from tonka beans (Figure 1). The pharmacological action of coumarins includes anti-cancer, anti-inflammatory [25], antiinfluenza, anti-tuberculosis [26], anti-HIV, antiviral, anti-Alzheimer, and antimicrobial [27] activities. Researchers now use coumarins as corrosion inhibitors because of the electronic structure, planarity, lone pairs of oxygen-powered electrons, and stability [28-30]. The life of mechanical hardware is established by good corrosion control. Corrosion inhibitors have become more important nowadays due to their use in industries. Natural inhibitors are considered much more eco-friendly than organic inhibitors. Organic inhibitors decrease the rate of corrosion by absorbing phosphorus, sulfur, oxygen, nitrogen atoms, or $\pi$-bonds on the surface of the metal through the active sites [31]. Quantum chemical computations based on the density function theory (DFT) have recently become a strong theoretical research method for examining the ability of organic molecules to inhibit corrosion. This tool provides a glimpse at physical insights into the mechanisms of corrosion inhibition [32]. 
Various natural compounds were explored as ecofriendly corrosion inhibitors for mild steel in a hydrochloric acid environment. However, literature reviews about coumarins as corrosion inhibitors for mild steel, in a hydrochloric acid environment are discussed here. Ehe usage of various types of coumarin as green inhibitors for mild steel is reviewed comprehensively. The available deficiency and the futurity domain of research in this direction have also been demonstrated in the current study.

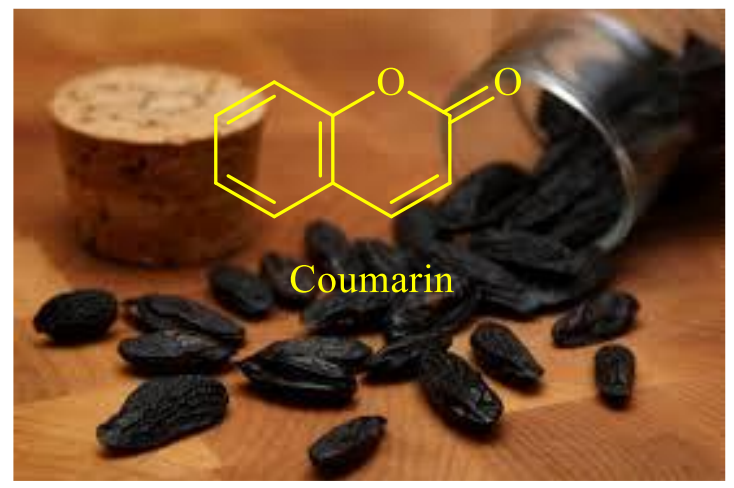

Figure 1. Tonka beans.

\section{Corrosion inhibition of mild steel by natural or organic synthetic compounds}

There are numerous reports available in the literature concerning the corrosion inhibition action of natural or organic synthetic compounds for mild steel in a broad range of corrosive media. The role of coumarin derivatives as green corrosion inhibitors on mild steel and the scientific advances are the major focus of the present work. The aim of this study is to review the literature centered on the protection of mild steel with environmentally benign inhibitors, the possible mechanism of the inhibition property, etc.

\subsection{Corrosion inhibition of mild steel by plant extracts}

Due to their success story in literature, plant extracts have the ability to substitute synthetic organic and inorganic inhibitors. The mechanism of action of green inhibitors depends on the structure of the active ingredient, so many researchers have put forward a variety of hypotheses to explain this phenomenon to date [33]. One suggestion is that in acid solutions, the active compounds form onium ions, are adsorbed on the mild steel surface's cathodic sites, and interfere with the cathodic reaction [34]. The active constituents of natural inhibitors differ, but their structures are closely connected to their organic counterparts, from one plant species to another. Garlic, for example, contains allyl propyl disulfide (Figure 2), mustard seeds contain alkaloid berberine with a long aromatic ring chain and an $\mathrm{N}$ atom in the ring, and carrots contain pyrrolidine in many areas, and castor seeds contain the ricinine alkaloid. 


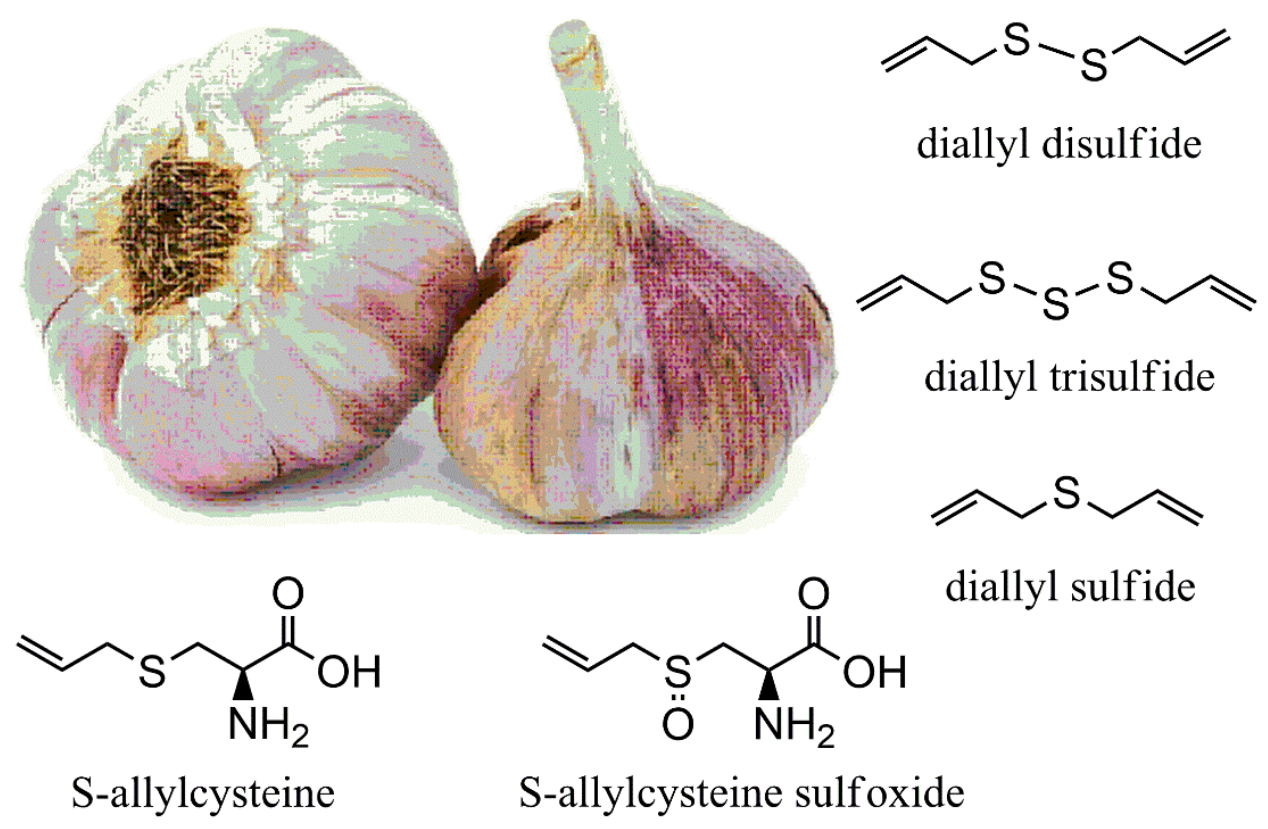

Figure 2. Garlic and its components.

Recent studies on the inhibition of mild steel by plant extracts by different authors are listed in Table 1. From the overview of the checked literature in the table, it can be observed that active research has been conducted on the application of plant extracts as green corrosion inhibitors to mild steel for a duration of approximately two years under study. Accordingly, the interpretation of the review description in Table 1 above is provided below $[35,36]$.

Table 1. Natural products as corrosion inhibitors for mild steel.

\begin{tabular}{|c|c|c|c|c|c|}
\hline Plant & Acid & $\begin{array}{l}\text { Temperature } \\
\text { effect on } I E\end{array}$ & $\begin{array}{c}\text { Concentration } \\
\text { effect on } I E\end{array}$ & Techniques & Ref. \\
\hline Molasses & $\mathrm{HCl}$ & $(\mathrm{CT})$ & $(+)$ & $(\mathrm{PP}),(\mathrm{EIS}) \&(\mathrm{WL})$ & [37] \\
\hline $\begin{array}{c}\text { Pentaclethra } \\
\text { macrophylla Bentham }\end{array}$ & $\mathrm{HCl}$ & $(-)$ & $(+)$ & $(\mathrm{EIS}) \&(\mathrm{WL})$ & {$[38]$} \\
\hline Aniba rosaeodora & $\mathrm{HCl}$ & (CT) & $(+)$ & $(\mathrm{PP}) \&(\mathrm{EIS})$ & {$[39]$} \\
\hline Adenopus breviflorus & $\mathrm{HCl}$ & $(-)$ & $(+)$ & (WL) & {$[40]$} \\
\hline Cucurbita maxima & $\mathrm{HCl}$ & $(+)$ & $(+)$ & $(\mathrm{WL})$ & {$[41]$} \\
\hline C. Papaya & $\mathrm{HCl}$ & $(\mathrm{CT})$ & $(+)$ & $(\mathrm{WL})$ & {$[42]$} \\
\hline Terminalia chebula & $\mathrm{HCl}$ & $(\mathrm{CT})$ & $(+)$ & $(\mathrm{PP}),(\mathrm{EIS}) \&(\mathrm{WL})$ & {$[43]$} \\
\hline $\begin{array}{l}\text { Turmeric and ginger } \\
\text { rhizomes }\end{array}$ & $\mathrm{HCl}$ & $(\mathrm{CT})$ & $(+)$ & $(\mathrm{PP}) \&(\mathrm{WL})$ & [44] \\
\hline Musa paradisiaca & $\mathrm{HCl}$ & $(\mathrm{CT})$ & $(+)$ & $(\mathrm{EIS}),(\mathrm{TP}) \&(\mathrm{WL})$ & {$[45]$} \\
\hline Pectin & $\mathrm{HCl}$ & $(+)$ & $(+)$ & $(\mathrm{PP}),(\mathrm{EIS}) \&(\mathrm{WL})$ & {$[46]$} \\
\hline
\end{tabular}




\begin{tabular}{|c|c|c|c|c|c|}
\hline Plant & Acid & $\begin{array}{l}\text { Temperature } \\
\text { effect on } I E\end{array}$ & $\begin{array}{c}\text { Concentration } \\
\text { effect on } I E\end{array}$ & Techniques & Ref. \\
\hline Ligularia fischeri & $\mathrm{HCl}$ & $(-)$ & $(+)$ & $(\mathrm{PP}),(\mathrm{EIS}) \&(\mathrm{WL})$ & [47] \\
\hline Phyllanthus amarus & $\mathrm{HCl}$ & $(-)$ & $(+)$ & $(\mathrm{PP}),(\mathrm{EIS}) \&(\mathrm{WL})$ & [48] \\
\hline Elaeis guineensis & $\mathrm{HCl}$ & $(-)$ & $(+)$ & $(\mathrm{PP}),(\mathrm{EIS}) \&(\mathrm{WL})$ & [49] \\
\hline Aloe vera & $\mathrm{HCl}$ & $(-)$ & $(+)$ & $(\mathrm{PP}),(\mathrm{EIS}) \&(\mathrm{WL})$ & {$[50]$} \\
\hline $\begin{array}{l}\text { Watermelon rind, seeds } \\
\text { and peel }\end{array}$ & $\mathrm{HCl}$ & $(-)$ & $(+)$ & $(\mathrm{PP}),(\mathrm{EIS}) \&(\mathrm{WL})$ & [51] \\
\hline Shrimps shell waste & $\mathrm{HCl}$ & $(-)$ & $(+)$ & $(\mathrm{PP}),(\mathrm{EIS}) \&(\mathrm{WL})$ & {$[52]$} \\
\hline $\begin{array}{l}\text { Solid waste from fresh } \\
\text { leaves of Banana, } \\
\text { sugarcane and water } \\
\text { melon hardcore }\end{array}$ & $\mathrm{HCl}$ & $(-)$ & $(+)$ & $(\mathrm{PP}),(\mathrm{EIS}) \&(\mathrm{WL})$ & {$[53]$} \\
\hline Scenedemus alge & $\mathrm{HCl}$ & $(-)$ & $(+)$ & $(\mathrm{PP}),(\mathrm{EIS}) \&(\mathrm{WL})$ & {$[54]$} \\
\hline $\begin{array}{c}\text { Bark of Rhizophora } \\
\text { apiculata }\end{array}$ & $\mathrm{HCl}$ & $(-)$ & $(+)$ & $(\mathrm{PP}),(\mathrm{EIS}) \&(\mathrm{WL})$ & {$[55]$} \\
\hline Dry olive leaves & $\mathrm{HCl}$ & $(-)$ & $(+)$ & $(\mathrm{PP}),(\mathrm{EIS}) \&(\mathrm{WL})$ & {$[56]$} \\
\hline Streptomycin & $\mathrm{HCl}$ & $(-)$ & $(+)$ & $(\mathrm{PP}),(\mathrm{EIS}) \&(\mathrm{WL})$ & {$[57]$} \\
\hline $\begin{array}{c}\text { Bark and leaves of } \\
\text { Neolamarckia cadamba }\end{array}$ & $\mathrm{HCl}$ & $(-)$ & $(+)$ & $(\mathrm{PP}),(\mathrm{EIS}) \&(\mathrm{WL})$ & {$[58]$} \\
\hline Seeds of Piper guineense & $\mathrm{HCl}$ & $(-)$ & $(+)$ & $(\mathrm{PP}),(\mathrm{EIS}) \&(\mathrm{WL})$ & [59] \\
\hline
\end{tabular}

(+) increase; (-) decrease; (CT) constant temperature; (PP) potentiodynamic polarization; (EIS) electrochemical impedance spectroscopy; (TP) Tafel polarization; (WL) weight loss.

In the Chinese patent, the corrosion inhibitor of sweet potato stems and lettuce flower stalks was used to provide pollution-reducing, biodegradable, environmentally safe products suffering no traditional synthesis drawbacks [60]. The use of fruit skin extracts (such as mango, cashew, passion fruit, and orange) as corrosion inhibitors for steel in an acid medium was linked to innovation by Gomes et al. [61]. Alcoholic extracts of eight plants, namely Lycium shawii, Teucrium oliverianum, Ochradenus baccatus, Anvillea garcinii, Cassia italica, Artemisia sieberi, Carthamus tinctorius and Tripleurospermum auriculatum, grown in Saudi Arabia, have been studied in $0.5 \mathrm{M} \mathrm{HCl}$ media using open circuit potential (OCP), Tafel plots and A.C. impedance for their corrosion inhibitory effect on mild steel. Both plant extracts prevent corrosion by adsorption on mild steel in acid media and act as mixed-type inhibitors [62]. Crude extracts (hexane, dichloromethane, methanol) from the bark of Cryptocarya nigra and three alkaloids called $N$-methylisococlaurine $\mathbf{1}, \quad N$ methyllaurotetanine $\mathbf{2}$ and atherosperminine $\mathbf{3}$ isolated from the extract of Cryptocarya nigra dichloromethane (CNDE) have been investigated in $1 \mathrm{M} \mathrm{HCl}$ solution for mild steel corrosion. An electrochemical impedance analysis showed that CNDE and $\mathbf{2}$ significantly 
reduced corrosion through a charge transfer mechanism with inhibition efficiency of $91.05 \%$ and $88.05 \%$, respectively. Potentiodynamic polarization data suggested that CNDE was an anodic inhibitor, whereas $\mathbf{2}$ was a mixed type inhibitor with predominant anodic efficacy [63]. In a $0.5 \mathrm{M} \mathrm{HCl}$ solution, tamarind shell tannin extract (TSTE) was examined for corrosion inhibition. Electrochemical impedance spectroscopy (EIS), potentiodynamic polarization (PP), and electrochemical noise measurement (ENM) were used for the analysis. Increasing the TSTE concentration increased the efficiency of inhibition to a maximum concentration of $1000 \mathrm{ppm}$. For the methanol (TME) extract and extraction in $70 \%$ acetone $30 \%$ water, the inhibition efficiencies were $87.77 \%$ and $86.34 \%$, respectively [64]. Using the weight loss method, the effect of neem leaf extract on the corrosion inhibition of mild steel in $0.1 \mathrm{M} \mathrm{HCl}$ solution was studied. The weight loss of mild steel surface was determined at various inhibitor concentrations. Using neem leaf extract as a corrosion inhibitor, the highest inhibition efficiency of 93.24\% was achieved. The inhibitor was adsorbed on mild steel surface by adsorption of phytochemical components that protect the metal surface from corroding. The corrosion rate decreases with an increase in inhibitor concentration from 0.001 to $0.0002 \mathrm{MPY}$ and with exposure time [35]. To predict the optimal control of mild steel corrosion in acid medium with bitter kola leaf extract as an inhibitor, the response surface methodology was applied. The experiment was conducted to explore the mutual interactions between the independent variables considered and the expected responses. In the corrosion inhibition study, thermometric, gravimetric, potentiodynamic polarization and electrochemical impedance spectroscopy were used. Optimization, thermometric, gravimetric, potentiodynamic polarization and electrochemical impedance spectroscopic techniques showed inhibition efficiencies of $88.24 \%, 86.81 \%$, $90 \%, 89.5 \%$ and $85.3 \%$, respectively. The extract of bitter kola leaf acted as a mixed-mode inhibitor [66].

\subsection{Corrosion inhibition of mild steel by synthesized organic compounds}

Corrosion inhibitors are of considerable practical significance because they are widely used to reduce metallic waste during manufacturing and to minimize the risk of material failure, both of which can lead to a sudden shutdown of industrial processes, resulting in additional costs [67]. To prevent metal dissolution and minimize acid consumption, it is also essential to use corrosion inhibitors [68-75]. Organic compounds that contain atoms of nitrogen, sulfur and oxygen are the majority of well-known acid inhibitors. The inhibitory effect of organic compounds on the dissolution of metallic species is usually associated with adsorption interactions between inhibitors and the metal surface [71, 72]. 1,5-Dimethyl-4((2-methylbenzylidene)amino)-2-phenyl-1 $H$-pyrazol-3( $2 H)$-one (DMPO) shown in Figure 3 was synthesized to be tested as an inhibitor of mild steel corrosion. 


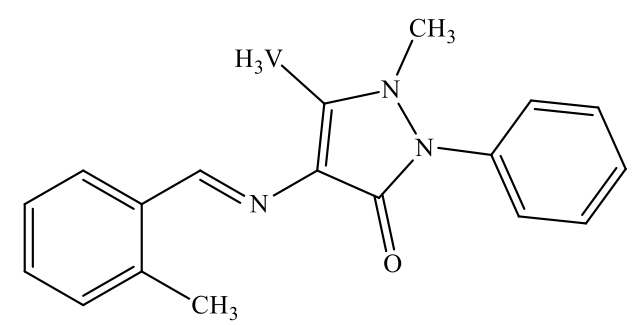

Figure 3. The chemical structure of DMPO.

Two pyrazole carboxamides called 5-(4-(dimethylamino)phenyl)-3-phenyl-4,5dihydro-1H-pyrazole-1-carboxamide DPC-1 and (E)-5-(4-(dimethylamino)phenyl)-3-(4(dimethylamino)styryl)-4,5-dihydro-1H-pyrazole-1-carboxamide DPC-2 (Figure 4) were studied as corrosion inhibitors of mild steel in hydrochloride acid solution using weight loss measurements, Tafel polarization curves, and electrochemical impedance spectroscopy (EIS). The results obtained show that DPC-1 and DPC-2 are effective corrosion inhibitors in a $1 \mathrm{M}$ solution of $\mathrm{HCl}$. As the concentration of inhibitors increases, the inhibition efficiency increases to $84.56 \%$ at $4 \cdot 10^{-4} \mathrm{~mol} \cdot \mathrm{L}^{-1}$ and $80 \%$ at $1.6 \cdot 10^{-4} \mathrm{~mol} \cdot \mathrm{L}^{-1}$ for DPC-1 and DPC-2 at $303 \mathrm{~K}$, respectively.

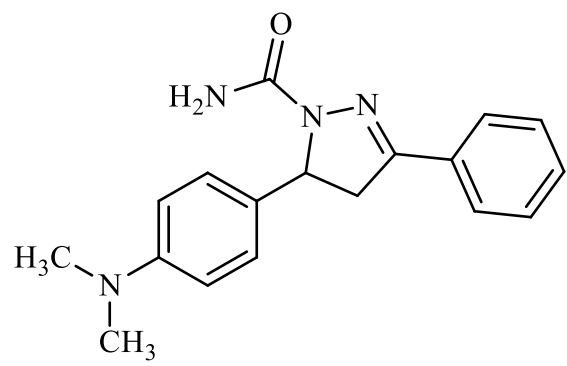

DPC-1

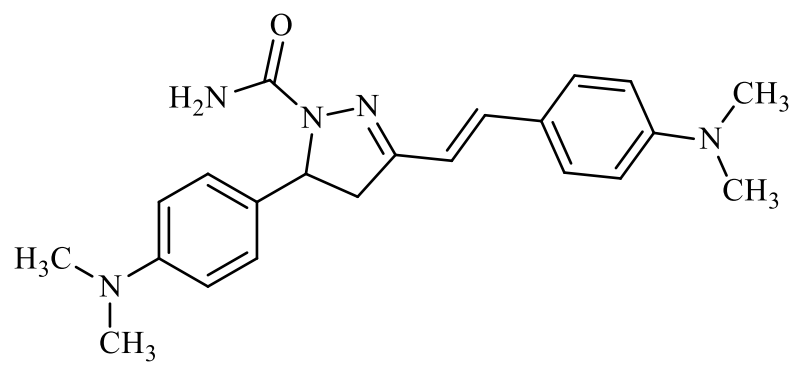

DPC-2

Figure 4. The chemical structures of DPC-1 and DPC-2.

Using DFT calculations [74], the relationship between the inhibition efficiency and the pyrazol parameters was investigated. The synthesis and characterization of a novel organic corrosion inhibitor (4-(3-mercapto-5,6,7,8-tetrahydro-[1,2,4]triazolo[4,3b][1,2,4,5]tetrazin-6-yl)phenol) shown in Figure 5 for mild steel in $1 \mathrm{M} \mathrm{HCl}$ were successfully documented for the first time.

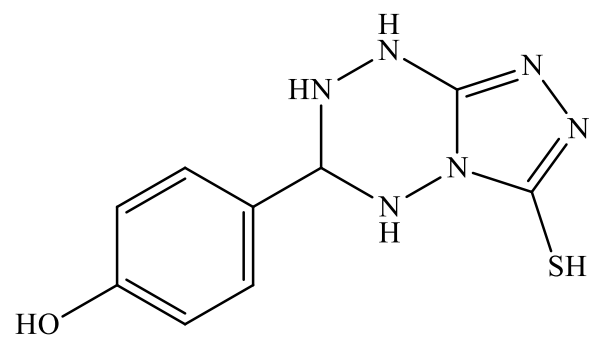

Figure 5. The chemical structure of 4-(3-mercapto-5,6,7,8-tetrahydro-[1,2,4]triazolo[4,3b] $[1,2,4,5]$ tetrazin-6-yl)phenol. 
S-Allyl-O,O'-diphenyldithiophosphate (SOD1), S-allyl-O,O'-dibenzyldithiophosphate (SOD2) and S-allyl-O,O'-di(2-phenylethyl)dithiophosphate (SOD3), as shown in Figure 6, were successfully synthesized and characterized by electrochemical measurements, weight loss calculation and scanning electron microscopy. They were shown to act as novel corrosion inhibitors for mild steel in $\mathrm{HCl}$ solution.

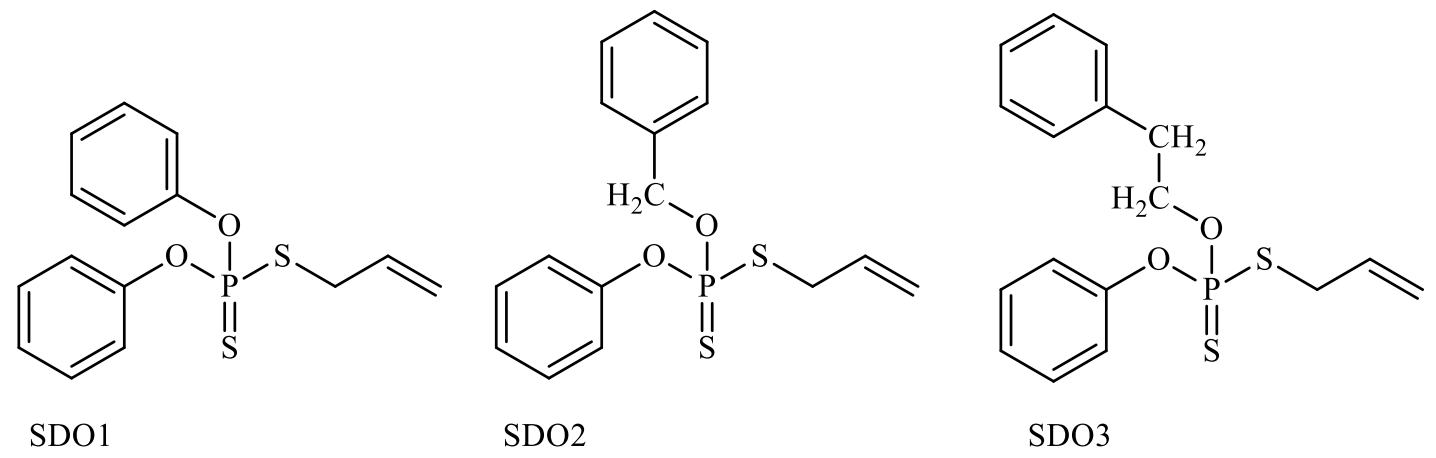

Figure 6. The chemical structures of SOD1, SOD2, and SOD3.

Potentiodynamic polarization measurements suggest that the synthesized inhibitors are effective inhibitors of mixed type. As inhibitor concentration increases, $\mathrm{HCl}$ concentration decreases, and temperature increases, the inhibition efficiency increases. The adsorption of SOD1 and SOD3 on mild steel surface is a mixed adsorption involving both physisorption and chemisorption, while the adsorption of SOD2 on mild steel surface belongs to chemical adsorption [76]. Using weight loss measurements, corrosion inhibition of mild steel in $0.5 \mathrm{M}$ hydrochloric acid by six synthesized heterocyclic compounds was tested. The inhibition efficiency exceeded 95\%. The excellent performance of the inhibitor was due to the formation of protective adsorption films on the steel surface. To explain the inhibition process, quantum chemical calculations were also performed [77]. Electrochemical impedance spectroscopy (EIS), potentiodynamic polarization, open circuit potential (OCP) and electrochemical frequency modulation (EFM) were used to study the acid corrosion inhibition process of mild steel in $1 \mathrm{M} \mathrm{HCl}$ by azelaic acid dihydrazide. Potentiodynamic polarization studies suggest that dihydrazide azelaic acid (Figure 7) is a mixed-type inhibitor. With increasing inhibitor concentration, the inhibition efficiency increases and reaches its maximum of $93 \%$ at $5 \cdot 10^{-3} \mathrm{M}$.

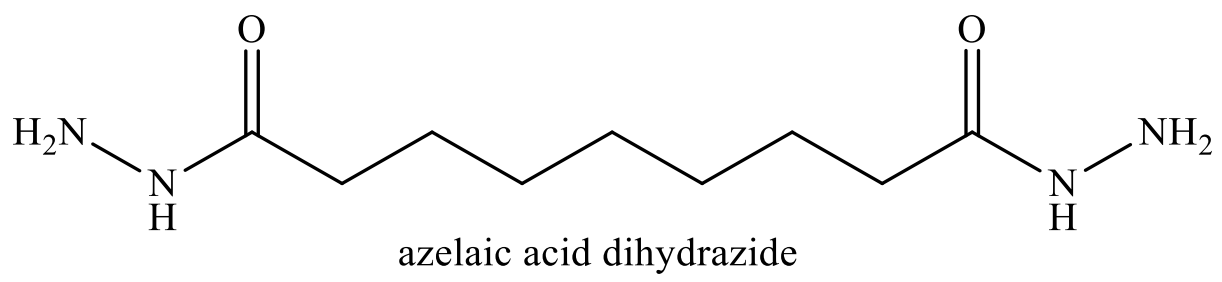

Figure 7. The chemical structure of azelaic acid dihydrazide. 
The adsorption of the inhibitor on a mild steel surface obeys Langmuir's adsorption isotherm. The effect of temperature on the corrosion behavior in the presence of $5 \cdot 10^{-3} \mathrm{M}$ inhibitor was studied in the $30-60^{\circ} \mathrm{C}$ temperature range. The results showed that the inhibition efficiency increased with an increase in inhibitor concentration and decreased with an increase in temperature [78]. A new research was reported in which two novel corrosion inhibitors BP-1 and BP-2 were synthesized (Figure 8) and their corrosion inhibition properties on mild steel (MS) in acid solution were evaluated by weight loss and electrochemical corrosion techniques.

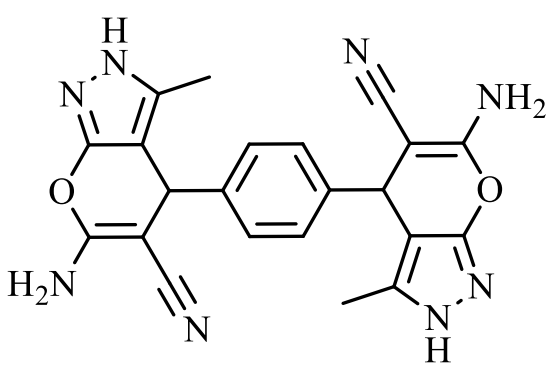

BP-1

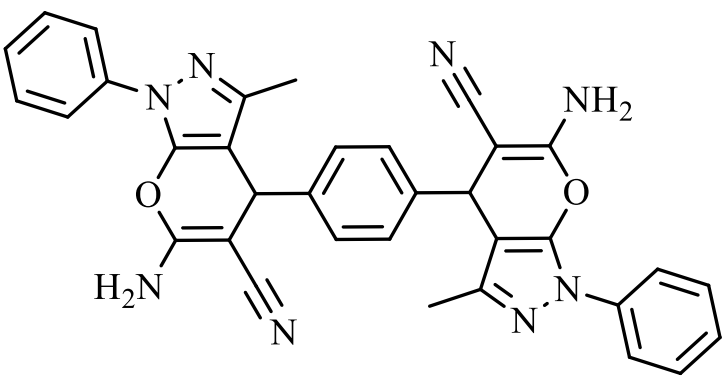

BP-2

Figure 8. The chemical structures of BP-1 and BP-2.

The corrosion test results show that both compounds inhibit corrosion through an adsorption mechanism and demonstrate more than 95\% inhibition efficiency at a low concentration of $1.72 \cdot 10^{-4} \mathrm{M}$. Simulated evidence from density functional theory helps link the experimental pattern with the theoretical analysis [79].

\subsection{Corrosion inhibition of mild steel by coumarin derivatives}

Researchers from a wide variety of industrial sectors have drawn attention to studies on the prevention of steel corrosion in acid environments and the problematic chemical processes that arise [80]. Steel corrosion is a common problem that directly affects its cost and protection. Mild steel corrosion can cause structural damage and alter the mechanical and chemical properties of plants, vessels, tubes, and other processing equipment. These results indicate that if an appropriate remedy from its analysis and testing is not found, corrosion will generate considerable costs. In different industries, the prevention of steel corrosion has played an important role, especially in the chemical and petrochemical processing industries that use steel. A new coumarin derivative was synthesized, $N, N-\left(\left(2 E, 2^{\prime} E\right)-2,2^{\prime}-(1,4-\right.$ phenylenebis(methanylylidene))bis(hydrazinecarbonothioyl))bis(2-oxo-2H-chromene-3carboxamide) PMBH (Figure 9), and its chemical structure was elucidated and confirmed using spectroscopic techniques (Infrared spectroscopy (IR), proton nuclear magnetic resonance $\left({ }^{1} \mathrm{H} \mathrm{NMR}\right)$ and carbon-13 nuclear magnetic resonance $\left.\left({ }^{13} \mathrm{C} \mathrm{NMR}\right)\right)$. 


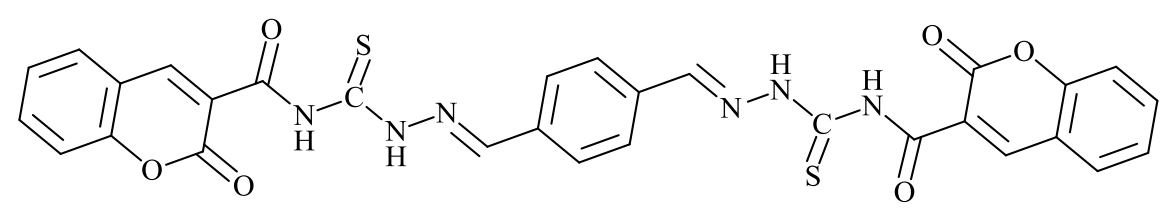

Figure 9. The chemical structure of $\mathrm{PMBH}$.

Using corrosion potential $\left(E_{\text {corr }}\right)$, potentiodynamic polarization, electrochemical impedance spectroscopy (EIS), and electrochemical frequency modulation (EFM) measurements, the corrosion inhibition effect of PMBH on mild steel at $1.0 \mathrm{M} \mathrm{HCl}$ was investigated. The findings obtained suggested that $\mathrm{PMBH}$ has promising inhibitive effects on mild steel corrosion in $1.0 \mathrm{M} \mathrm{HCl}$ over all of the conditions tested. Scanning electron microscopy (SEM) was used before and after immersion to examine the morphology of mild steel in a $1.0 \mathrm{M} \mathrm{HCl}$ solution containing $0.5 \mathrm{mM}$ of PMBH. In the presence of PMBH [81], surface analysis showed an increase in corrosion resistance. The method of inhibition of acid corrosion of mild steel in $1 \mathrm{M} \mathrm{HCl}$ by 4-[(2-amino-1,3,4-thiadiazol-5-yl)methoxy]coumarin (ATC) (Figure 10) was investigated using the technique of weight loss and scanning electron microscopy (SEM).

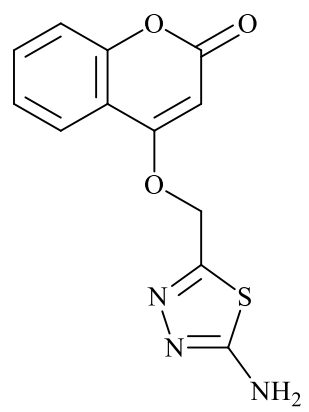

Figure 10. The chemical structure of ATC.

The findings suggested that with an increase in inhibitor concentration, inhibition efficiencies increased and decreased with an increase in temperature. The synthesized macromolecule is an excellent inhibitor for acid solution materials. This macromolecule has a maximum inhibition efficiency of up to $96 \%$ at $0.5 \mathrm{mM}$ that decreases at higher temperatures. Quantum chemical parameters were measured and addressed, such as highest occupied orbital molecular energy, lowest unoccupied orbital molecular energy $\left(E_{\mathrm{HOMO}}\right.$ and $E_{\mathrm{LUMO}}$, respectively) and dipole moment $(\mu)$. The results showed that with an increase in both the $E_{\mathrm{HOMO}}$ and $\mu$ values but with a decrease in the $E_{\mathrm{LUMO}}$ value [82], the corrosion inhibition efficiency improved. Coumarin derivative 4-((4-amino-5-thio-1,2,4-triazol-3yl)methyl)coumarin (ATTC) (Figure 11) was synthesized as a novel eco-friendly corrosion inhibitor and tested by weight loss, electrochemical impedance spectroscopy (EIS) and potentiodynamic (PD) polarization techniques on mild steel in $1 \mathrm{M}$ hydrochloric acid solution. 


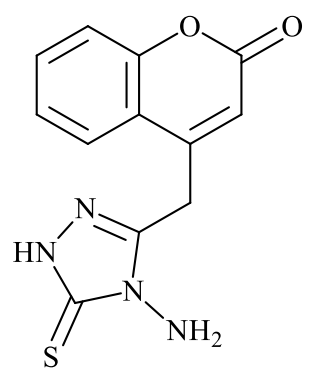

Figure 11. The chemical structure of ATTC.

The corrosion analysis results show that at a concentration of $0.5 \mathrm{mM}$, ATTC inhibits corrosion by the adsorption mechanism and displays an inhibition efficiency of about $96 \%$. From the morphological study of the protective film on the mild steel surface by means of scanning electron microscopy (SEM) technique, it was verified that adsorption of ATTC molecules occurs on the mild steel surface by chemisorption, which further decreases the corrosion rate. The gaseous state stability of the ATTC molecule was investigated and it was found to exist in thio and mercapto forms. The thio form has a higher stability state compared to the mercapto form, based on density function theory (DFT) findings. On the basis of thermodynamic parameters, the conversion of thio form to mercapto form was found to be spontaneous and endothermic [83]. The anti-corrosion capability of the synthesized coumarin, i.e. 2-(coumarin-4-yloxy)acetohydrazide (EFCI) (Figure 12), for mild steel (MS) in $1 \mathrm{M}$ solution of hydrochloric acid was tested using the weight loss method. The effect of temperature on the corrosion rate was investigated and some thermodynamic parameters were determined. The findings suggested that with an increase in inhibitor concentration, the inhibition efficiency increased and decreased with an increase in temperature. The inhibition efficiency of this eco-friendly inhibitor reaches $94.7 \%$ at the maximum concentration used.

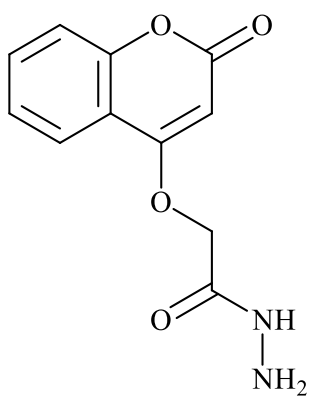

Figure 12. The chemical structure of EFCI.

A Langmuir adsorption isotherm has been found to describe the adsorption of the inhibitor on the mild steel surface. For quantum-chemical calculations of parameters such as $E_{\mathrm{HOMO}}$ (highest occupied molecular orbital energy), $E_{\mathrm{LUMO}}$ (lowest unoccupied molecular orbital energy) and $\mu$ (dipole moment), the density function theory (DFT) was used and the results obtained were considered to be compatible with the experimental findings [84]. 3((4-nitrobenzylidene)amino)coumarin (Figure 13), a comparatively inexpensive and stable 
organic compound, was used as an excellent corrosion inhibitor for mild steel in hydrochloric acid. The effectiveness of inhibition was measured by the weight loss method. The inhibition efficiency of the inhibitor was $71.4 \%$ at the maximum concentration studied [85].

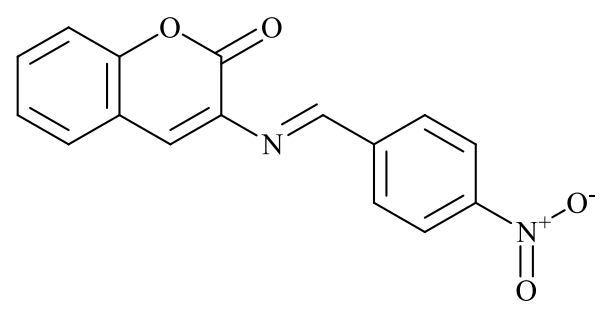

Figure 13. The chemical structure of 3-((4-nitrobenzylidene)amino)coumarin.

A cost-effective novel hydrazine-derived coumarin 4-(6methylcoumarin)acetohydrazide (MCA) was synthesized, characterized, and tested as an inhibitor for the corrosion of mild steel surface in an acid environment by weight loss and scanning electron microscopy (SEM) techniques. The results showed that the synthesized inhibitor (Figure 14) can inhibit the corrosion of mild steel surface in a $1 \mathrm{M}$ hydrochloric acid environment. The corrosion inhibition efficiency of MCA increases with increasing MCA concentration and decreases with increasing temperature. SEM analysis showed the formation of a protective layer from MCA molecules on the surface of mild steel. Adsorption of the MCA molecules on the mild steel surface in the presence of hydrochloric acid environment obeyed the Langmuir isotherm. Density functional theory (DFT) calculations were used to study the relationship between molecular structure and inhibition efficiency and they were found to be in good agreement [86].

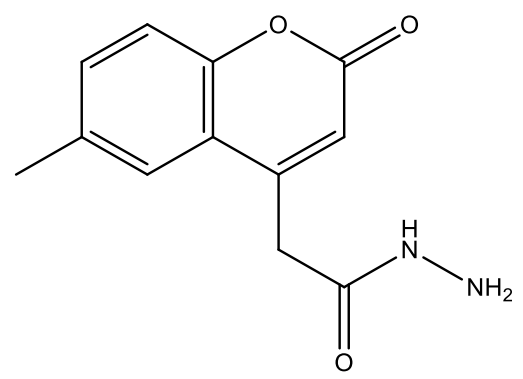

Figure 14. The chemical structure of MCA.

A new corrosion inhibitor derived from coumarin-3-amine namely 3-((2chlorobenzylidene)amino)coumarin as in Figure 15, was synthesized and characterized by CHN elemental analysis in addition to Fourier transform infrared and nuclear magnetic resonance techniques. The anti-corrosion ability of 3-((2-chlorobenzylidene)amino)coumarin to inhibit the impact of corrosion was demonstrated. 3-((2-Chlorobenzylidene)amino)coumarin was employed as a good corrosion inhibitor for mild steel in $\mathrm{HCl}$ solution. The inhibition efficiency was $74.6 \%$ as determined by the weight loss method [87]. 


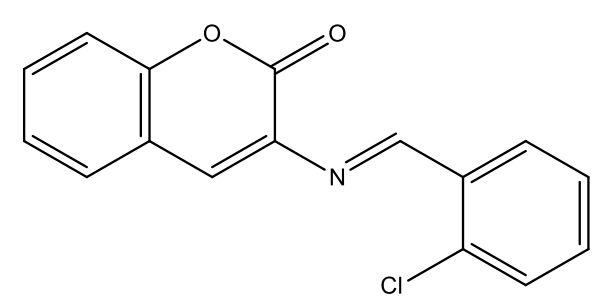

Figure 15. The chemical structure of 3-((2-chlorobenzylidene)amino)coumarin.

Two coumarin derivatives, namely, 3-(3-benzyl-4-hydroxy-2-thioxo-3,4-dihydro- $2 \mathrm{H}$ 1,3-thiazin-6-yl)-8-methoxy-2H-chromen-2-one (BTMC) and 3-(3-benzyl-4-hydroxy-2 thioxo-3,4-dihydro-2H-1,3-thiazin-6-yl)-2H-chromen-2-one (BTC) (Figure 16) were synthesized, characterized and applied as potential corrosion inhibitors for mild steel (MS) in $1 \mathrm{M}$ hydrochloric acid. Different techniques including potentiodynamic polarization (PDP), electrochemical impedance spectroscopy (EIS) and weight loss (WL) measurements were applied in order to prove the inhibition potential of BTMC and BTC against mild steel corrosion. PDP investigation suggests the mixed mode of inhibition by the coumarin derivatives studied. These compounds prevented the metal from the corrosive attack of chloride anions $\left(\mathrm{Cl}^{-}\right)$by getting adsorbed on the metal surface following the Langmuir isotherm adsorption model. The change in surface morphology was studied by scanning electron microscopy (SEM) and Electron Dispersion Spectroscopy (EDS). Organic molecules formed a non-crystalline protective layer on the metal surface which was confirmed by X-ray Diffraction Analysis (XRD). The corrosive solution applied for descaling or acid pickling process dissolved the metal surface until the inhibitor was applied. The UV-Vis spectrum confirms the formation of a complex between the inhibitor and the iron cations present in the electrolytic medium. WL measurement revealed that BTMC and BTC exhibit a high inhibition efficiency (IE\%) of $93.59 \%$ and $92.17 \%$, respectively, at their optimum concentration (300 ppm) at $298 \mathrm{~K}$. Density functional theory (DFT) calculations and Monte Carlo (MC) simulations were employed to envisage the interactions of synthesized inhibitors with metal surface along with corrosive species present in the corrosive environment. In addition, The Fukui function and local softness indices were computed for the determination of the most plausible nucleophilic and electrophilic attack sites [88].

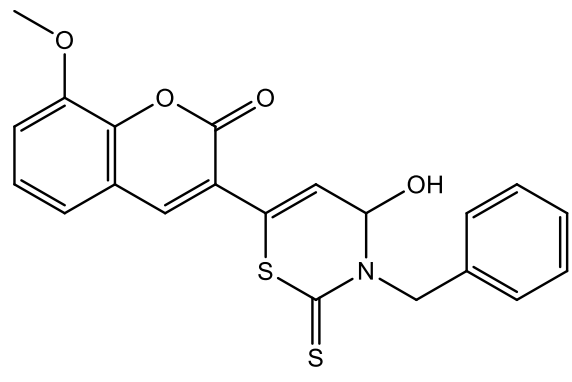

BTMC

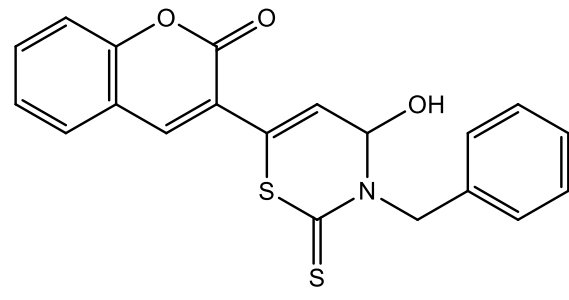

BTC

Figure 16. The chemical structures of BTMC and BTC. 
The corrosion inhibition behavior of mild steel (MS) in $1 \mathrm{M}$ hydrochloric acid in the presence of 4-hydroxycoumarin (4HC) (Figure 17) and potassium iodide (KI) was investigated using the weight loss method and electrochemical techniques. The inhibitive performance of $4 \mathrm{HC}$ is considerably enhanced by the addition of KI. The addition of KI to different concentrations of $4 \mathrm{HC}$ intensified its efficiency through considerable reduction in the mass loss, corrosion current density, double layer capacitance, and increase in charge transfer resistance. The calculated synergism parameter " $S$ " is greater than unity, thereby proving the fact that the improvement in inhibition efficiency of $4 \mathrm{HC}$, generated by the addition of KI, is due to synergism [89].

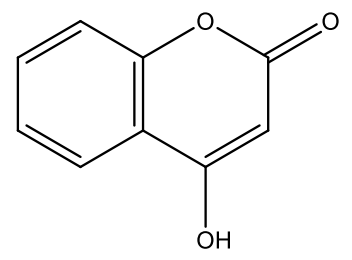

Figure 17. The chemical structure of $4 \mathrm{HC}$.

The inhibition efficiency of a new coumarin derivative (Figure 18), namely 2-(6methylcoumarin-4-yl)- $N^{\prime}$-(3-nitrobenzylidene)acetohydrazide (MCNAH), in controlling the corrosion of mild steel in $1 \mathrm{M}$ hydrochloric acid solution was investigated by gravimetric techniques at various temperatures $(303,313,323$ and $333 \mathrm{~K})$. The impact of immersion time and temperature on the inhibition performance of MCNAH was also studied. MCNAH was synthesized and its chemical structure was elucidated by magnetic resonance spectroscopy (MRS) and Fourier transform infrared spectroscopy (FT-IR). The experimental results suggest that MCNAH is an excellent corrosion inhibitor for mild steel in $1 \mathrm{M}$ hydrochloric acid environment. The synthesized inhibitor (MCNAH) has the ability to impede the corrosion of mild steel in $1 \mathrm{M}$ hydrochloric acid environment at low and high concentrations. The inhibitive efficiency was found to increase with increasing concentration of MCNAH and decrease with increasing time and temperature. The thermodynamic parameters were estimated and discussed. The adsorption of the synthesized inhibitor on the surface of the tested mild steel in the presence of $\mathrm{HCl}$ obeyed the Langmuir adsorption isotherm. The relationship between the structure of the new synthesized inhibitor and its inhibitive effects was investigated using theoretical calculations. The experimental and density functional theory (DFT) calculation results are in good agreement. The results clearly show that the inhibition mechanism involves a blocking mechanism of action of the inhibitor [90]. 


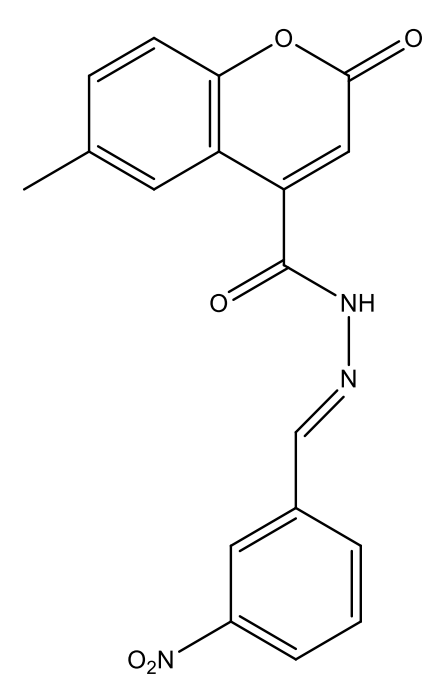

Figure 18. The chemical structure of MCNAH.

The corrosion protection of mild steel in $1.0 \mathrm{M} \mathrm{HCl}$ medium with azo-coumarin dyes (Figure 19) as inhibitors was studied by electrochemical impedance and potentiodynamic polarization measurements. The azocoumarin dyes 8-10 were synthesized by the coupling reactions between diazonium salts of aniline derivatives with 4-hydroxycoumarin under basic conditions. The result showed that the inhibition efficiency was found to increase (average $I E$ was shown to be $>80 \%$ ) with increasing concentration of the azocoumarin dyes, and their adsorption over mild steel surface was found to obey the Langmuir adsorption isotherm. Furthermore, the Langmuir adsorption isotherm parameters made it evident that corrosion inhibition occurs through physisorption mode of interaction. After corrosion evaluation, mild steel's surface morphology was screened via SEM-EDX analysis which showed an improved surface in the presence of azo-coumarin dye derivatives [91].

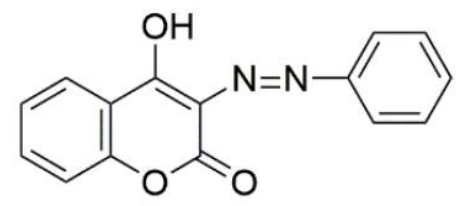

(8)<smiles>O=c1oc2ccccc2c(O)c1N=Nc1ccc(Br)cc1</smiles>

(9)<smiles>O=c1oc2ccccc2c(O)c1N=Nc1ccc(Cl)cc1</smiles>

(10)

Figure 19. The chemical structures of azo-coumarins.

\section{DFT}

Quantum chemical methods have already proven to be very helpful in evaluating the molecular structure as well as in elucidating the electronic structure and reactivity that could be realistic in the quantitative structure-activity relationship (QSAR) approach for the design of novel high-efficiency inhibitors [92-94]. These quantum-chemical computational simulations based on DFT of acceptable models have increasingly made this prevailing method available to corrosion scientists for theoretical corrosion inhibition mechanism 
investigation. Using a variety of quantum chemical descriptors, such computations have been commonly used to examine the molecular electronic structures of a wide range of adsorption-type inhibitors, which have provided valuable physical insights into corrosion inhibition mechanisms [95]. The efficiency of inhibition is therefore associated with the molecular and structural parameters that can be determined through theoretical calculations such as chemical selectivity, reactivity, and distribution of charges. The frontier molecular orbital, HOMO (highest occupied molecular orbital) energy, LUMO (lowest unoccupied molecular orbital) energy, chemical potential and hardness, electronegativity, and a number of electron transfers are other quantum chemical effects, among others are computed. The main objective of computational corrosion inhibitor research is to gain insight into the mechanisms by which the metal-corrodent interaction is retarded by inhibitors applied to a fluid aggressive environment. Indeed, the efficacy of the overall process depends on the surface of the metal, the corrosive media, the molecular and electronic structure, and the inhibitor concentration, as well as the temperature and other environmental considerations [98].

A molecule's ability to donate electrons to the free d orbital of metal is correlated with the energy of the highest occupied molecular orbital (HOMO). Compounds are more capable of donating electrons with higher $E_{\text {HOMO }}$. The energy of the lowest unoccupied molecular orbital (LUMO) is linked to the ability of the metal to receive electrons. Lower values show a greater propensity to accept electrons. Furthermore, positive values are associated with chemisorption, whereas negative physisorption values are associated with chemisorption [97]. The energy gap is another important parameter:

$$
\Delta E=E_{\mathrm{HOMO}}-E_{\mathrm{LUMO}}
$$

The lower $\Delta E$, the more reactive the molecule, which is associated with increased adsorption of inhibitor molecules to a metal surface [98]. A significant parameter which gives information about polarity in a bond is also the dipole moment $(\mu)$. As the value of $\mu$ increases, corrosion inhibition performance increases due to stronger dipole-dipole interactions with the metal surface, resulting in stronger adsorption and effective inhibition of corrosion [99]. Information on the resistance of a molecule to charge transfer and on the capacity of a molecule to receive electrons is given by chemical hardness $(F)$ and softness $(\sigma)$. They are evaluated based on these equations:

$$
\begin{gathered}
\eta=-\frac{E_{\mathrm{HOMO}}-E_{\mathrm{LUMO}}}{2} \\
\sigma=\frac{1}{\eta}
\end{gathered}
$$

A higher $\sigma$ value means that the molecule is weaker and has a greater propensity to donate electrons to the metal [100]. For the measurement of ionization potential (IP) and 
electron affinity (EA), the energy of HOMO and LUMO orbitals can be used using the following equations:

$$
\begin{aligned}
& I_{\mathrm{P}}=-E_{\text {HOMO }} \\
& E_{\mathrm{A}}=-E_{\mathrm{LUMO}}
\end{aligned}
$$

The determined values are utilized for calculating the electronegativity $(\chi)$ [101]:

$$
\chi=-\frac{E_{\mathrm{HOMO}}+E_{\mathrm{LUMO}}}{2}
$$

A high $\chi$ value implies a good ability to draw electrons from the metal, leading to higher interactions and greater protection from corrosion. The last measured parameter is the electron fraction transferred $(\Delta N)$ :

$$
\Delta N=\frac{\chi_{\mathrm{Fe}}-\chi_{\text {in }}}{2\left(\eta_{\mathrm{Fe}}+\eta_{\mathrm{in}}\right)}
$$

where $\chi_{\mathrm{Fe}}$ equals $7 \mathrm{eV}$ and $\eta_{\mathrm{Fe}}=0$.

If $\Delta N>0$, the electrons are passed to the metal from the molecule and if $\Delta N<0$, to the molecule from the metal. For the compounds tested, the electron fraction values were transferred if the transmission from the metal to the molecules was negative [97-101].

Four new bis(coumarin) compounds (Figure 20) were prepared and their structures were confirmed using elemental analysis, FTIR, ${ }^{1} \mathrm{H}$ NMR, and mass spectroscopy. The corrosion inhibition tendencies of the prepared compounds in inhibiting the carbon steel corrosion in $0.5 \mathrm{M} \mathrm{H}_{2} \mathrm{SO}_{4}$ were investigated using potentiodynamic polarization, electrochemical impedance measurements, and quantum chemical methods. The results showed that the prepared compounds are efficient and perform their action as mixed type corrosion inhibitors, and their corrosion inhibition tendencies were increased on rising their concentration and temperature of measurement. The adsorption of the prepared inhibitors on the carbon steel surface was chemisorption and obeyed the Langmuir adsorption isotherm. The results of quantum chemical calculations and the electrochemical measurements were in good agreement [102].

Computational calculations of coumarin and quercetin (Figure 21) were performed using the Density Functional Theory (DFT) in order to investigate their inhibition potentials. The coumarin molecule demonstrated a greater corrosion inhibition potentials compared to the quercetin molecule. The corrosion potentials were predicted using quantum chemical parameters like the energy of the highest occupied molecular orbital $\left(\mathrm{E}_{\mathrm{HOMO}}\right)$ and energy of the lowest unoccupied molecular orbital ( $\left.\mathrm{E}_{\mathrm{LUMO}}\right)$, ionization potential (I), Fukui indices ( $\mathrm{f}+$ and f- ) and global hardness [103]. 
<smiles>Cc1cc(=O)oc2cc(OCCCOc3ccc4c(C)cc(=O)oc4c3)ccc12</smiles>

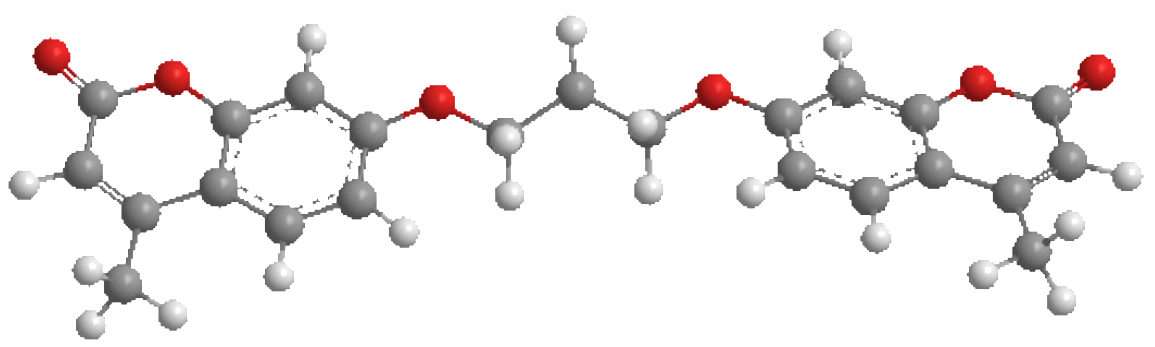

2d (I)

3d (I)<smiles>Cc1cc(=O)oc2cc(OCc3cccc(COc4ccc5c(C)cc(=O)oc5c4)c3)ccc12</smiles>

2d (II)

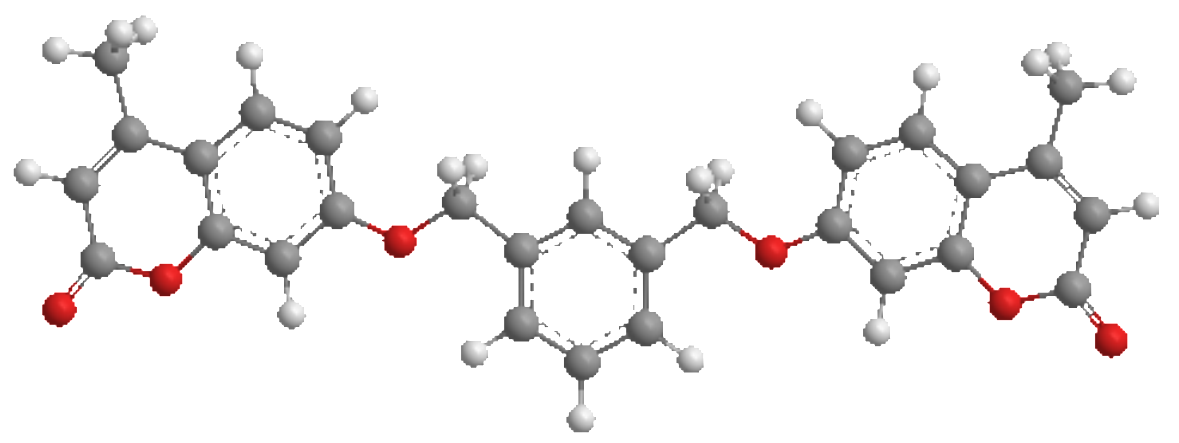<smiles>Cc1cc(=O)oc2cc(OCc3ccc(COc4ccc5c(C)cc(=O)oc5c4)cc3)ccc12</smiles>

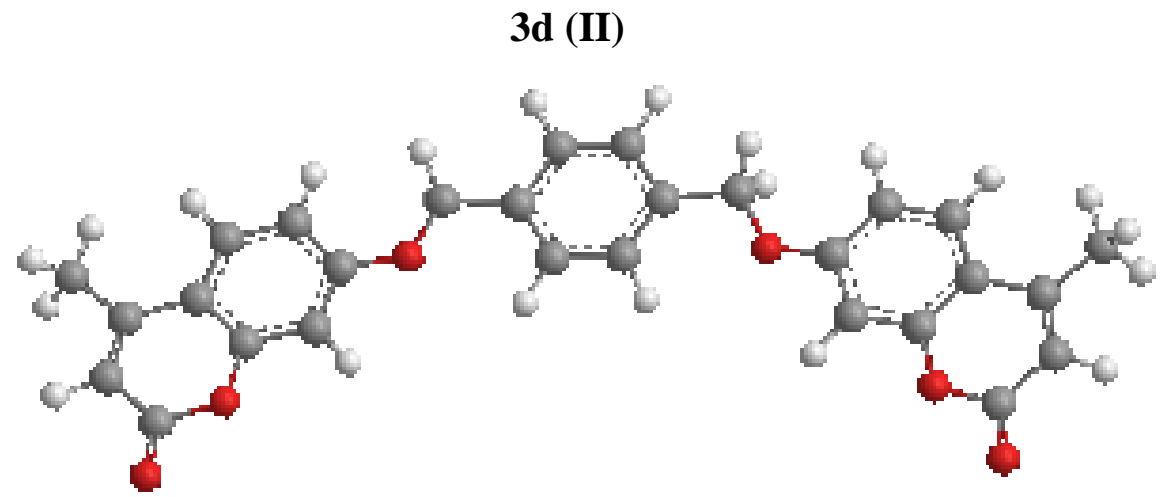

2d (III)<smiles>Cc1cc(=O)oc2cc(OCc3ccc4cc(COc5ccc6c(C)cc(=O)oc6c5)ccc4c3)ccc12</smiles>

2d (IV)

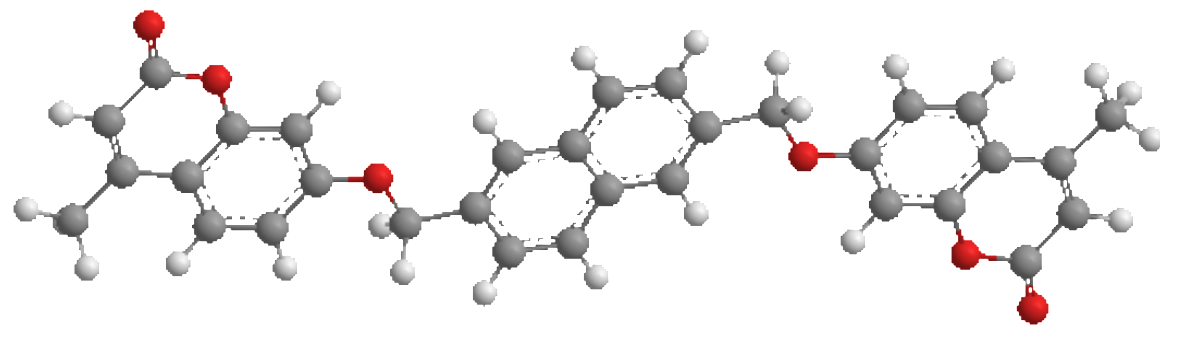

3d (IV)

Figure 20. The chemical structures of biscoumarins ( $2 \mathrm{~d}$ and $3 \mathrm{~d})$. 


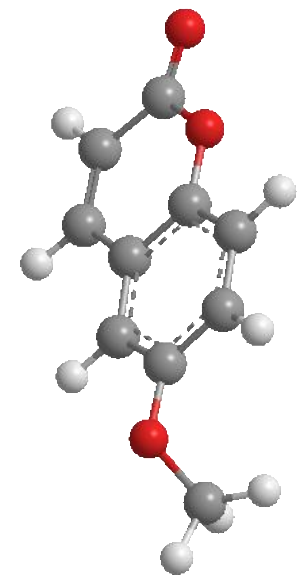

Coumarin

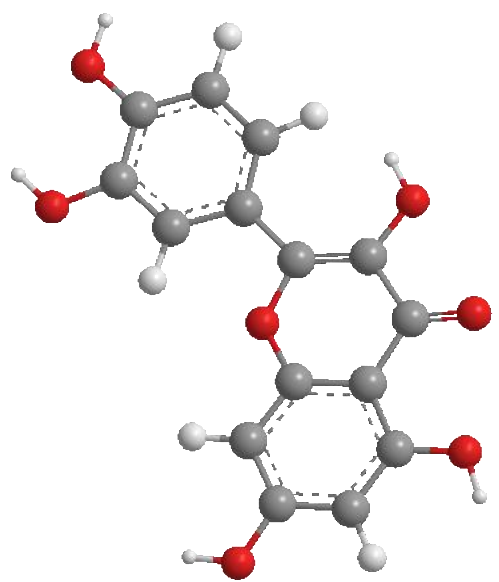

Quercetin

Figure 21. The optimized structures of coumarin and quercetin.
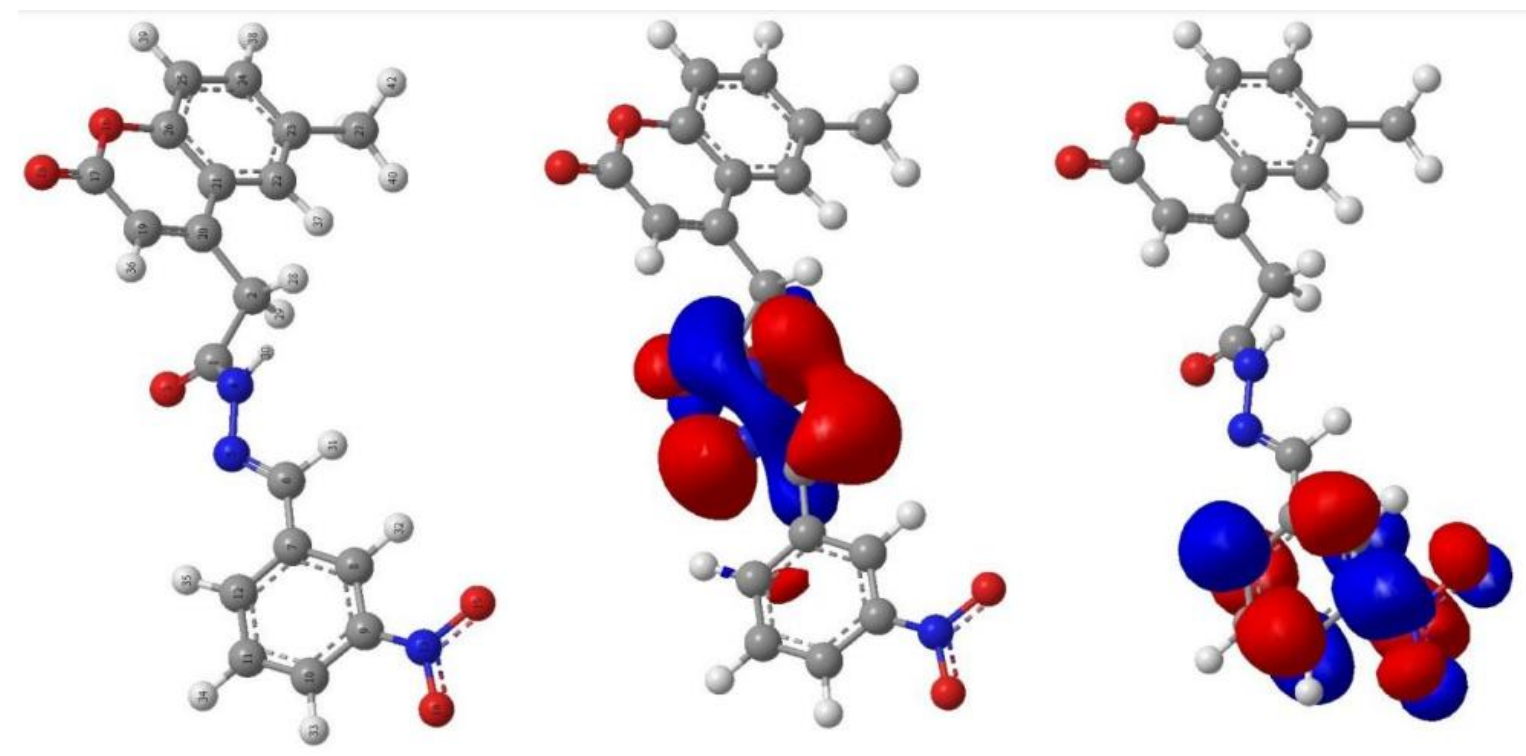

Figure 22. The 3-dimensional structure, HOMO and LUMO frontiers of 2-(6methylcoumarin-4-yl)- $N^{\prime}$-(3-nitrobenzylidene)acetohydrazide.

Generally, the HOMO is associated with the ability of a molecule to release an electron. The $E_{\text {Номо }}$ with high value indicate the ability to donate electrons. On the other hand, low $E_{\mathrm{LUmo}}$ values are associated with the ability to accept electrons from molecules of a donor.

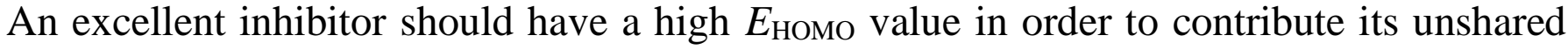
electrons to the vacant d-orbital of iron (mild steel); moreover, a good inhibitor must have a low $E_{\mathrm{LUMO}}$ value in order to accept the unshared electrons transferred from the mild steel surface to the free orbitals of inhibitor molecules, and also the energy gap should be the smallest. This investigation denotes that the new synthesized inhibitor has significant inhibition characteristics due to the low energy gap of $3.277 \mathrm{eV}$ as shown in Table 2. The optimized geometrical structure, HOMO and LUMO are given in Figure 22. The dipole 
moment is another significant factor that has a considerable impact on the inhibitive characteristics of the inhibitor molecules on the mild steel surface. Generally, the dipole moment is related to the inhibitive performance. This inhibitor molecule under investigation has a dipole moment value of -4.52 indicating that this studied inhibitor has good inhibition efficiency. The 3-dimensional structure, HOMO and LUMO frontiers of 2-(6methylcoumarin-4-yl)- $N^{\prime}$-(3-nitrobenzylidene)acetohydrazide are demonstrated in Figure 22. As shown in Figure 22, the HOMO distribution is on average around the isomethine group and the LUMO distribution in on average around the nitrobenzene ring [91].

Table 2. Calculated quantum properties for the most stable conformation of 2-(6-methylcoumarin-4-yl)- $N^{\prime}-$ (3-nitrobenzylidene)acetohydrazide.

\begin{tabular}{cc}
\hline Function & Values \\
\hline$E_{\mathrm{HOMO}}$ & $-8.755 \mathrm{eV}$ \\
$E_{\mathrm{LUMO}}$ & $-5.478 \mathrm{eV}$ \\
$E_{\mathrm{HOMO}}-E_{\mathrm{LUMO}}$ & $-3.277 \mathrm{eV}$ \\
Dipole Moment $(\mu)$ & $-4.52 \mathrm{Debye}$ \\
$I=-E_{\mathrm{HOMO}}$ & $8.755 \mathrm{eV}$ \\
$A=-E_{\mathrm{LUMO}}$ & $5.478 \mathrm{eV}$ \\
$\eta=-0.5\left(E_{\mathrm{HOMO}}-E_{\mathrm{LUMO}}\right)$ & 5836.1 \\
$\sigma=1 / \eta$ & 0.6103 \\
$\chi=-0.5\left(E_{\mathrm{HOMO}}+E_{\mathrm{LUMO}}\right)$ & 7.1165 \\
$\Delta N=\frac{\chi_{\mathrm{Fe}}-\chi_{\text {in }}}{2\left(\eta_{\mathrm{Fe}}+\eta_{\mathrm{in}}\right)}$ & 0.2883 \\
\hline
\end{tabular}

\section{Mechanism of corrosion inhibition}

Inhibitor molecules were adsorbed on the surface of mild steel by displacing water molecules that were adsorbed on the surface of mild steel by inhibitor molecules. Generally, the electrostatic attraction between the charges of mild steel surface and molecules is called physisorption, on the other hand the transfer of electron pairs from the inhibitor molecules to the unoccupied d-orbital of mild steel surface that forms coordination bonds is called chemisorption. In the corrosive environment, the mild steel surface has negative charges which results from adsorbed chloride ions on the mild steel surface. The results clearly show that the inhibition mechanism involves a blocking mechanism of inhibitor action.

The inhibitor is chemically adsorbed on the metal surface to form a protective thin film or chemical bonds by a reaction between the inhibitor and the metal. The adsorption mechanism of organic inhibitors can occur via one of the following routes: 1st, charged 
molecules and a metal attract electrostatically; 2nd, by interaction between unpaired electrons and the metal surface; and 3rd, interaction between $\pi$-electrons and the metal surface. Organic inhibitors protect the metal surface by blocking cathodic or anodic reactions or both and forming insoluble complexes. The inhibition efficiency of the corrosion inhibitor against the corrosion of mild steel in $1 \mathrm{M}$ hydrochloric acid can be explained in terms of the number of adsorption sites, charge density, molecular size, mode of interaction with the metal surface and ability to form an insoluble metal complex. The $\pi$ electrons of the double bonds and free electrons on the oxygen and nitrogen atoms form chemical bonds with the metal surface as shown in Figure 23 [81].

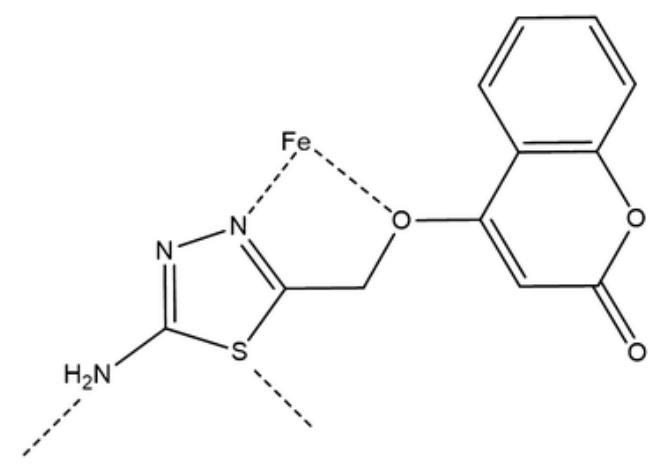

Figure 23. The suggested mechanism of action of ATC as a corrosion inhibitor.

\section{Conclusion}

In various industrial applications, various types of inhibitors, such as drugs, chemical compounds and plant extracts, have already been applied where their non-toxicity has been indirectly confirmed. Plant extracts are enriched with various phytochemical components, but only a few specific components are responsible for the protection of metals. It is therefore proposed to carry out the separation and evaluate separate components. Organic corrosion inhibitors incorporating heteroatoms and $\pi$-electron moieties are very effective corrosionfighting compounds. The reviewed literature clearly indicates that coumarin derivatives may be used to achieve a new way of inhibiting corrosion processes. Theoretically calculated structures can make it possible to synthesize coumarin derivatives with the highest corrosion inhibition efficacy based on prediction. In order to explore the relationship between the structure and corrosion inhibition, advanced research should also be focused on using more innovative characterization techniques based on theoretical simulation, such as density functional theory (DFT). This insight will help us to explain the corrosion inhibition mechanism and to design the exploration of a wide range of new and possible sustainable corrosion inhibitors. 


\section{References}

1. K. Zhang, W. Yang, X. Yin, Y. Chen, Y. Liu, J. Le and B. Xu, Amino acids modified konjac glucomannan as green corrosion inhibitors for mild steel in $\mathrm{HCl}$ solution, Carbohydr. Polym., 2018, 181, 191-199. doi: 10.1016/j.carbpol.2017.10.069

2. D. Mahmood, A.K. Al-Okbi, M.M. Hanon, K.S. Rida, A.F. Alkaim, A.A. Al-Amiery, A. Kadhum and A.A.H. Kadhum, Carbethoxythiazole corrosion inhibitor: as an experimentally model and DFT theory, J. Eng. Appl. Sci., 2018, 13, 3952-3959. doi: 10.36478/jeasci.2018.3952.3959

3. A. Kadhim, E.T. Salim, S.M. Fayadh, A.A. Al-Amiery, A.A.H. Kadhum and A. Mohamad, Effect of Multipath Laser Shock Processing on Microhardness, Surface Roughness And Wear Resistance of 2024-T3 Al Alloy, Sci. World J., 2014, 1-6. doi: $\underline{10.1155 / 2014 / 490951}$

4. A. Alobaidy, A. Kadhum, S. Al-Baghdadi, A. Al-Amiery, A. Kadhum, E. Yousif and A.B. Mohamad, Eco-friendly corrosion inhibitor: experimental studies on the corrosion inhibition performance of creatinine for mild steel in $\mathrm{HCl}$ complemented with quantum chemical calculations, Int. J. Electrochem. Sci., 2015, 10, 3961-3972.

5. S. Junaedi, A.A.H. Kadhum, A. Al-Amiery, A.B. Mohamad and M.S. Takriff, Synthesis and characterization of novel corrosion inhibitor derived from oleic acid: 2-Amino-5Oleyl 1,3,4-Thiadiazol (AOT), Int. J. Electrochem. Sci., 2012, 7, 3543-3554.

6. A.Y.I. Rubaye, K.S. Rida, A.Q. Salam and A. Al-Amiery, Acetamidocoumarin as a based eco-friendly corrosion inhibitor, Int. J. ChemTech Res., 2016, 9, 39-47.

7. H.J. Habeeb, H.M. Luaibi, T.A. Abdullah, R.M. Dakhil, A.A.H. Kadhum and A.A. AlAmiery, Case study on thermal impact of novel corrosion inhibitor on mild steel, Case Stud. Therm. Eng., 2018, 12, 64-68. doi: 10.1016/j.csite.2018.03.005

8. S.S. Al-Taweel, K.W.S. Al-Janabi, H.M. Luaibi, A.A. Al-Amiery and T.S. Gaaz, Evaluation and characterization of the symbiotic effect of benzylidene derivative with titanium dioxide nanoparticles on the inhibition of the chemical corrosion of mild steel, Int. J. Corros. Scale Inhib., 2019, 8, no. 4, 1149-1169. doi: 10.17675/2305-6894-2019$\underline{8-4-21}$

9. F. Mansfeld, Use of electrochemical impedance spectroscopy for the study of corrosion protection by polymer coatings, J. Appl. Electrochem., 1995, 25, 187-202. doi: $10.1007 / \mathrm{bf00262955}$

10. A. Kahyarian, A. Schumaker, B. Brown and S. Nesic, Acidic corrosion of mild steel in the presence of acetic acid: Mechanism and prediction, Electrochim. Acta, 2017, 258, 639-652. doi: $10.1016 /$ j.electacta.2017.11.109

11. H.R. Obayes, A.A. Al-Amiery, G.H. Alwan, T.A. Abdullah, A.A.H. Kadhum and A.B. Mohamad, Sulphonamides as corrosion inhibitor: experimental and DFT studies, J. Mol. Struct., 2017, 1138, 27-34. doi: 10.1016/j.molstruc.2017.02.100 
12. D.M. Jamil, A.K. Al-Okbi, S.B. Al-Baghdadi, A.A. Al-Amiery, A. Kadhim, T.S. Gaaz, A.A.H. Kadhum and A.B. Mohamad, Experimental and theoretical studies of Schiff bases as corrosion inhibitors, Chem. Cent. J., 2018, 12, no. 7, 1-7. doi: 10.1186/s13065$\underline{018-0376-7}$

13. M.H.O. Ahmed, A.A. Al-Amiery, Y.K. Al-Majedy, A.A.H. Kadhum, A.B. Mohamad and T.S. Gaaz, Synthesis and characterization of a novel organic corrosion inhibitor for mild steel in $1 \mathrm{M}$ hydrochloric acid, Results Phys., 2018, 8, 728-733. doi: 10.1016/j.rinp.2017.12.039

14. T.A. Salman, D.S. Zinad, S.H. Jaber, M. Shayaa, A. Mahal, M.S. Takriff and A.A. AlAmiery, Effect of 1,3,4 thiadiazole scafold on the corrosion inhibition of mild steel in acid medium: an experimental and computational study, J. Bio Tribo-Corros., 2019, 5, no. 48, 1-11. doi: $10.1007 / \mathrm{s} 40735-019-0243-7$

15. O.K. Abiola, N.C. Oforka, E.E. Ebenso, and N.M. Nwinuka, Eco- friendly corrosion inhibitors the inhibitive action of Delonuix regia extract for the corrosion of aluminum in acid media, Anti-Corros. Methods Mater., 2007, 54, no. 4, 219-224.

16. H.J. Habeeb, H.M. Luaibi, R.M. Dakhil, A.A.H. Kadhum, A.A. Al-Amiery and T.S. Gaaz, Development of new corrosion inhibitor tested on mild steel supported by electrochemical study, Results Phys., 2018, 8, 1260-1267. doi: 10.1016/j.rinp.2018.02.015

17. A. Kadhim, A.K. Al-Okbi, D.M. Jamil, A. Qussay, A.A. Al-Amiery, T.S. Gaas, A.A.H. Kadhum, A.B. Mohamad and M.H. Nassir, Experimental and theoretical studies of benzoxazines corrosion inhibitors, Results Phys., 2017, 7, 4013-4019. doi: 10.1016/j.rinp.2017.10.027

18. D. Liu, Y.B. Qiu, Y. Tomoe, K. Bando and X.P. Guo, Interaction of inhibitors with corrosion scale formed on $\mathrm{N} 80$ steel in $\mathrm{CO}_{2}$-saturated $\mathrm{NaCl}$ solution, Mater. Corros., 2011, 62, no. 12, 1153-1158. doi: 10.1002/maco.201106075

19. E. Barmatov, T. Hughes and M. Nagl, Performance of organic corrosion inhibitors on carbon steels and high alloys in 4M hydrochloric acid, NACE Int. Corros. Conf. Expo, 2015, 1-14.

20. Y.P. Khodyrev, E. Batyeva, E. Badeeva, E. Platova, L. Tiwari and O. Sinyashin, The inhibition action of ammonium salts of $\mathrm{O}, \mathrm{O}^{\prime}$-dialkyldithiophosphoric acid on carbon dioxide corrosion of mild steel, Corros. Sci., 2011, 53, 976-983. doi: 10.1016/j.corsci.2010.11.030

21. A.A. Al-Amiery and L.M. Shaker, Corrosion inhibition of mild steel using novel pyridine derivative in $1 \mathrm{M}$ hydrochloric acid, Koroze Ochr. Mater., 2020, 64, no. 2, 5964. doi: $\underline{10.2478 / \mathrm{kom}-2020-0009}$

22. A.A. Al-Amiery, A.A.H. Kadhum, A.H.M. Alobaidy, A.B. Mohamad and P.S. Hoon, Novel corrosion inhibitor for mild steel in $\mathrm{HCl}$, Materials, 2014, 7, no. 2, 662-672. doi: $\underline{10.3390 / \mathrm{ma} 7020662}$ 
23. A.A. Al-Amiery, A.A.H. Kadhum, A.B. Mohamad and S. Junaedi, A novel hydrazinecarbothioamide as a potential corrosion inhibitor for mild steel in $\mathrm{HCl}$, Materials, 2013, 6, no. 4, 1420-1431. doi: 10.3390/ma6041420

24. V.S. Sastri, Corrosion Inhibitors, Principles and Application, John Wiley and Sons, 1998.

25. D. Egan, R. O'Kennedy, E. Moran, D. Cox, E. Prosser and R.D. Thornes, The pharmacology, metabolism, analysis, and applications of coumarin and coumarin-related compounds, Drug Metab Rev., 1990, 22, 503-529. doi: $10.3109 / 03602539008991449$

26. T. Devji, C. Reddy, C. Woo, S. Awale, S. Kadota and D. CorrioMoniz, Pancreatic Anticancer activity of a novel geranylgeranylated coumarin derivative, Bioorg. Med. Chem. Lett., 2011, 21, 57705773. doi: 10.1016/j.bmcl.2011.08.005

27. J-Y. Yeh, M.S. Coumar, J-T. Horng, H-Y. Shiao and H-L. Lee, Anti-influenza drug discovery: structure-activity relationship and mechanistic insight into novel angelicin derivatives, J. Med. Chem., 2010, 53, 1519-1533. doi: 10.1021/jm901570x

28. A.A. Al-Amiery, A.A.H. Kadhum, A. Kadihum, A.B. Mohamad, C.K. How and S. Junaedi, Inhibition of mild steel corrosion in sulfuric acid solution by new Schiff base, Materials, 2014, 7, no. 2, 787-804. doi: 10.3390/ma7020787

29. A.B. Mohamad, A.A.H. Kadhum, A.A. Al-Amiery, L.C. Ying and A.Y. Musa, Synergistic of a coumarin derivative with potassium iodide on the corrosion inhibition of aluminum alloy in $1.0 \mathrm{M} \mathrm{H}_{2} \mathrm{SO}_{4}$, Met. Mater. Int., 2014, 20, 459-467. doi: 10.1007/s12540-014-3008-3

30. H.R. Obayes, G.H. Alwan, A.H.MJ. Alobaidy, A.A. Al-Amiery, A.A.H. Kadhum and A.B. Mohamad, Quantum chemical assessment of benzimidazole derivatives as corrosion inhibitors, Chem. Cent. J., 2014, 8, 21, 1-8. doi: 10.1186/1752-153X-8-21

31. A.A. Al-Amiery, A.A.H. Kadhum, A.B. Mohamad, A.Y. Musa and C.J. Li, Electrochemical study on newly synthesized chlorocurcumin as an inhibitor for mild steel corrosion in hydrochloric acid, Materials, 2013, 6, no. 12, 5466-5477. doi: 10.3390/ma6125466

32. G. Gece, The use of quantum chemical methods in corrosion inhibitor studies, Corros. Sci., 2008, 50, no. 11, 2981-2992. doi: 10.1016/j.corsci.2008.08.043

33. A. Kadhim, A.A. Al-Amiery, R. Alazawi, M.K.S. Al-Ghezi and R.H. Abass, Corrosion inhibitors. A review, Int. J. Corros. Scale Inhib., 2021, 10, no. 1, 54-67. doi: $\underline{10.17675 / 2305-6894-2021-10-1-3}$

34. M. Hanoon, D.S. Zinad, A.M. Resen and A.A. Al-Amiery, Gravimetrical and surface morphology studies of corrosion inhibition effects of a 4-aminoantipyrine derivative on mild steel in a corrosive solution, Int. J. Corros. Scale Inhib., 2020, 9, no. 3, 953-966. doi: $10.17675 / 2305-6894-2020-9-3-10$

35. C. Verma and M.A. Quraishi, Adsorption behavior of 8,9-bis(4(dimethyl amino)phenyl)benzo[4,5]imidazo[1,2-a]pyridine6,7-dicarbonitrile on mild steel surface in $1 \mathrm{M} \mathrm{HCl}$, J. Assoc. Arab Univ. Basic Appl. Sci., 2017, 22, 55-61. doi: 10.1016/j.jaubas.2016.01.003 
36. M. Chigondo and F. Chigondo, Recent Natural Corrosion Inhibitors for Mild Steel: An Overview, J. Chem., 2016, 6208937, 1-7. doi: 10.1155/2016/6208937

37. P. Slepski, H. Gerengi, A. Jazdzewska, J. Orlikowski and K. Darowicki, Simultaneous impedance and volumetric studies and additionally potentiodynamic polarization measurements of molasses as a carbon steel corrosion inhibitor in $1 \mathrm{M}$ hydrochloric acid solution, Constr. Build. Mater., 2014, 52, 482-487. doi: 10.1016/j.conbuildmat.2013.11.059

38. L.A. Nnanna, I.O. Owate and E.E. Oguzie, Inhibition of mild steel corrosion in $\mathrm{HCl}$ solution by Pentaclethra macrophylla Bentham extract, Int. J. Mater. Eng., 2014, 4, no. 5, 171-179. doi: 10.5923/j.ijme.20140405.02

39. M. Chevalier, F. Robert, N. Amusant, M. Traisnel, C. Roos, and M. Lebrini, Enhanced corrosion resistance of mild steel in $1 \mathrm{M}$ hydrochloric acid solution by alkaloids extract from Aniba rosaeodora plant: electrochemical, phytochemical and XPS studies, Electrochim. Acta, 2014, 131, 96-105. doi: 10.1016/j.electacta.2013.12.023

40. A. Adewuyi, A. Gopfert, and T. Wolff, Succinyl amide gemini surfactant from Adenopus breviflorus seed oil: A potential corrosion inhibitor of mild steel in acid medium, Ind. Crops Prod., 2014, 52, 439-449. doi: 10.1016/j.indcrop.2013.10.045

41. K. Anbarasi and V.G. Vasudha, Corrosion inhibition potential of Cucurbita maxima plant extract on mild steel in acid media, Chem. Sci. Rev. Lett., 2014, 3, no. 9, 45-51.

42. N. Kavitha, P. Manjula and N. Anandha, Synergistic effect of C. Papaya leaves extract$\mathrm{Zn}^{2+}$ in corrosion inhibition of mild steel in aqueous medium, Res. J. Chem. Sci., 2014, 4, no. 8, 88-93.

43. E.E. Oguzie, M.A. Chidiebere, K.L. Oguzie, C.B. Adindu and H. Momoh-Yahaya, Biomass extracts for materials protection: corrosion inhibition of mild steel in acid media by Terminalia chebula extracts, Chem. Eng. Commun., 2014, 201, no. 6, 790-803. doi: 10.1080/00986445.2013.790816

44. A.M. Al-Fakih, M. Aziz and H.M. Sirat, Turmeric and ginger as green inhibitors of mild steel corrosion in acid medium, J. Mater. Environ. Sci., 2015, 6, no. 5, 1480-1487.

45. G. Ji, S. Anjum, S. Sundaram and R. Prakash, Musa paradisica peel extract as green corrosion inhibitor for mild steel in $\mathrm{HCl}$ solution, Corros. Sci., 2015, 90, 107-117. doi: 10.1016/j.corsci.2014.10.002

46. M.V. Fiori-Bimbi, P.E. Alvarez, H. Vaca and C.A. Gervasi, Corrosion inhibition of mild steel in HCL solution by pectin, Corros. Sci., 2015, 92, 192-199. doi: 10.1016/j.corsci.2014.12.002

47. M. Prabakaran, S.-H. Kim, K. Kalaiselvi, V. Hemapriya and I.-M. Chung, Highly efficient Ligularia fischeri green extract for the protection against corrosion of mild steel in acid medium: electrochemical and spectroscopic investigations, J. Taiwan Inst. Chem. Eng., 2016, 59, 553-562. doi: 10.1016/j.jtice.2015.08.023 
48. K.K. Anupama, K. Ramya and A. Joseph, Electrochemical and computational aspects of surface interaction and corrosion inhibition of mild steel in hydrochloric acid by Phyllanthus amarus leaf extract (PAE), J. Mol. Liq., 2016, 216, 146-155. doi: $\underline{\text { 10.1016/j.molliq.2016.01.019 }}$

49. M.H. Hussin, A.A. Rahim, M.N.M. Ibrahim and N. Brosse, The capability of ultrafiltrated alkaline and organosolv oil palm (Elaeis guineensis) fronds lignin as green corrosion inhibitor for mild steel in $0.5 \mathrm{M} \mathrm{HCl}$ solution, Measurement, 2016, 78, 90103. doi: $10.1016 /$ j.measurement.2015.10.007

50. A.K. Singh, S. Mohapatra and B. Pani, Corrosion inhibition effect of Aloe vera gel: gravimetric and electrochemical study, J. Ind. Eng. Chem., 2016, 33, 288-297. doi: 10.1016/j.jiec.2015.10.014

51. N.A. Odewunmi, S.A. Umoren and Z.M. Gasem, Watermelon waste products as green corrosion inhibitors for mild steel in $\mathrm{HCl}$ solution, J. Environ. Chem. Eng., 2015, 3, 286296. doi: $10.1016 /$ j.jece. 2014.10.014

52. M.H.M. Hussein, M.F. El-Hady, H.A.H. Shehata, M.A. Hegazy and H.H.H. Hefni, Preparation of some eco-friendly corrosion inhibitors having antibacterial activity from seafood waste, J. Surfactants Deterg., 2013, 16, 233-242. doi: 10.1007/s11743-012$\underline{1395-3}$

53. M. Ismail, A.S. Abdulrahman and M.S. Hussain, Solid Waste As Environmental Benign Corrosion Inhibitors in Acid medium, Int. J. Eng. Sci. Technol., 2011, 3, 1742-1748.

54. A. Khanra, M. Srivastava, M.P. Rai and R. Prakash, Application of Unsaturated Fatty Acid Molecules Derived from Microalgae toward Mild Steel Corrosion Inhibition in $\mathrm{HCl}$ Solution: A Novel Approach for Metal-Inhibitor Association, ACS Omega, 2018, 3, 12369-12382. doi: 10.1021/acsomega.8b01089

55. A.Y. El-Etre, Inhibition of acid corrosion of carbon steel using aqueous extract of olive leaves, J. Colloid Interface Sci., 2007, 314, 578-583. doi: 10.1016/j.jcis.2007.05.077

56. K.W. Tan and M.J. Kassim, A correlation study on the phenolic profiles and corrosion inhibition properties of mangrove tannins (Rhizophora apiculata) as affected by extraction solvents, Corros. Sci., 2011, 53, 569-574. doi: 10.1016/j.corsci.2010.09.065

57. S.K. Shukla, A.K. Singh, I. Ahamad and M.A. Quraishi, Streptomycin: A commercially available drug as corrosion inhibitor for mild steel in hydrochloric acid solution, Mater. Lett., 2009, 63, 819-822. doi: 10.1016/j.matlet.2009.01.020

58. P.B. Raja, A.K. Qureshi, A. Abdul Rahim, H. Osman and K. Awang, Neolamarckia cadamba alkaloids as eco-friendly corrosion inhibitors for mild steel in $1 \mathrm{M} \mathrm{HCl}$ media, Corros. Sci., 2013, 69, 292-301. doi: 10.1016/j.corsci.2012.11.042

59. E.E. Oguzie, C.B. Adindu, C.K. Enenebeaku, C.E. Ogukwe, M.A. Chidiebere and K.L. Oguzie, Natural products for materials protection: Mechanism of corrosion inhibition of mild steel by acid extracts of piper guineense, J. Phys. Chem. C, 2012, 116, 13603-13615. doi: 10.1021/jp300791s

60. Extract Corrosion Inhibitor of Sweet Potato Stems and Lettuce Flower Stalks and Preparation Method Thereof, Patent No. CN102492948B, 31 July 2013. 
61. J.A. Ponciano Gomes, J. CardosoRocha and E. D'Elia, Use of Fruit Skin Extracts as Corrosion Inhibitors and Process for Producing Same, U.S. Patent US8926867B2, 6 January 2015.

62. M.S. Al-Otaibi, A.M. Al-Mayouf, M. Khan, A.A. Mousa, S.A. Al-Mazroa and H.Z. Alkhathlan, Corrosion inhibitory action of some plant extracts on the corrosion of mild steel in acid media, Arab. J. Chem., 2014, 7, no. 3, 340-346. doi: 10.1016/j.arabjc.2012.01.015

63. M. Faiz, A. Zahari, K. Awang and H. Hussin, Corrosion inhibition on mild steel in $1 \mathrm{M}$ $\mathrm{HCl}$ solution by Cryptocarya nigra extracts and three of its constituents (alkaloids), RSC $A d v ., 2020,10,65476562$. doi: 10.1039/C9RA05654H

64. A. Abdulmajid, T. Hamidon, A. Abdul Rahim and M. Hussin, Tamarind shell tannin extracts as green corrosion inhibitors of mild steel in hydrochloric acid medium, Mater. Res. Express, 2019, 6, 106579. doi: 10.1088/2053-1591/ab3b87

65. A. Okewale and F. Omoruwuo, Neem Leaf Extract as a Corrosion Inhibitor on Mild Steel in Acid solution, Int. J. Eng. Res. Afr., 2018, 35, 208-220. doi: 10.4028/www.scientific.net/jera.35.208

66. V.C. Anadebe, O.D. Onukwuli, M. Omotioma and N.A. Okafor, Optimization and Electrochemical Study on the Control of Mild Steel Corrosion in Hydrochloric Acid Solution with Bitter Kola Leaf Extract as Inhibitor, S. Afr. J. Chem., 2018, 71, 51-61. doi: $10.17159 / 0379-4350 / 2018 / \mathrm{v} 71 \mathrm{a} 7$

67. D.N. Sing and A.K. Dey, Synergistic effects of inorganic and organic cations on inhibitive performance of propargyl alcohol on steel dissolution in boiling hydrochloric acid solution, Corrosion, 1993, 49, 594-600. doi: 10.5006/1.3316090

68. E. Yousif, Y.F. Win, A.H. Al-Hamadani, A. Al-Amiery, A.A.H. Kadhum and A.B. Mohamad, Furosemide as an environmental-friendly inhibitor of corrosion of zinc metal in acid medium: Experimental and theoretical studies, Int. J. Electrochem. Sci., $2015, \mathbf{1 0}, 1708-1718$.

69. S.B. Al-Baghdadi, F.T.M. Noori, W.K. Ahmed and A.A. Al-Amiery, Thiadiazole as a potential corrosion inhibitor for mild steel in $1 \mathrm{M} \mathrm{HCl}, J$. Adv. Electrochem., 2016, 2, $67-69$.

70. F.H. Khaled, Investigation of the inhibitive effect of ortho-substituted on corrosion of iron in 0.5 $\mathrm{M} \mathrm{H}_{2} \mathrm{SO}_{4}$ solutions, Mater. Chem. Phys., 2003, 82, 949-960. doi: 10.1016/j.matchemphys.2003.08.007

71. K.F. Al-Azawi, I.M. Mohammed, S.B. Al-Baghdadi, T.A. Salman, H.A. Issa, A.A. AlAmiery, T.S. Gaaz and A.A.H. Kadhum, Experimental and quantum chemical simulations on the corrosion inhibition of mild steel by 3-((5-(3,5-dinitrophenyl)-1,3,4thiadiazol-2-yl)imino)indolin-2-one, Results Phys., 2018, 9, 278-283. doi: $\underline{10.1016 / j . r i n p .2018 .02 .055}$ 
72. S. Junaedi, A. Al-Amiery, A. Kadihum, A.H. Kadhum and A. Mohamad, Inhibition Effects of a Synthesized Novel 4-Aminoantipyrine Derivative on the Corrosion of Mild Steel in Hydrochloric Acid Solution together with Quantum Chemical Studies, Int. J. Mol. Sci., 2013, 14, 11915-11928. doi: 10.3390/ijms140611915

73. A. Sehmi, H.B. Ouici, A. Guendouzi, M. Ferhat, O. Benali and F. Boudjellal, Corrosion Inhibition of Mild Steel by newly Synthesized Pyrazole Carboxamide Derivatives in $\mathrm{HCl}$ Acid Medium: Experimental and Theoretical Studies, J. Electrochem. Soc., 2020, 167, 155508.

74. M.H.O. Ahmed, A.A. Al-Amiery, Y.K. Al-Majedy, A.A.H. Kadhum, A.B. Mohamad and T.S. Gaaz, Synthesis and characterization of a novel organic corrosion inhibitor for mild steel in $1 \mathrm{M}$ hydrochloric acid, Results Phys., 2018, 8, 728-733. doi: 10.1016/j.rinp.2017.12.039

75. C. Lai, B. Xie, L. Zou, X. Zheng, X. Ma and S. Zhu, Adsorption and corrosion inhibition of mild steel in hydrochloric acid solution by S-allyl-O,O'-dialkyldithiophosphates, Results Phys., 2017, 7, 2017, 3434-3443

76. S.K. Ahmed, W.B. Ali and A.A. Khadom, Synthesis and investigations of heterocyclic compounds as corrosion inhibitors for mild steel in hydrochloric acid, Int. J. Ind. Chem., 2019, 10, 159-173. doi: 10.1007/s40090-019-0181-8

77. A.A. Al-Amiery, F.A.B. Kassim, A.A.H. Kadhum and A.B. Mohamad, Synthesis and characterization of a novel eco-friendly corrosion inhibition for mild steel in $1 \mathrm{M}$ hydrochloric acid, Sci. Rep., 2016, 6, 19890. doi: 10.1038/srep19890

78. P. Singh, M. Kumar, M. Quraishi, J. Haque and G. Singh, Bispyranopyrazoles as Green Corrosion Inhibitors for Mild Steel in Hydrochloric Acid: Experimental and Theoretical Approach, ACS Omega, 2018, 3, no. 9, 11151-11162. doi: 10.1021/acsomega.8b01300

79. B.E.A. Rani and B.B.J. Basu, Green inhibitors for corrosion protection of metals and alloys: An overview, Int. J. Corros., 2012, 2, 1-15. doi: 10.1155/2012/380217

80. A.A.H. Kadhum, A.B. Mohamad, L.A. Hammed, A.A. Al-Amiery, N.H. San and A.Y. Musa, Inhibition of mild steel corrosion in hydrochloric acid solution by new coumarin, Materials, 2014, 7, no. 6, 4335-4348. doi: $\underline{\text { 10.3390/ma7064335 }}$

81. K. Al-Azawi, S. Al-Baghdadi, A. Mohamed, A.A. Al-Amiery, T.K. Abed, S.A. Mohammed, A.H. Kadhum and A. Mohamad, Synthesis, inhibition effects and quantum chemical studies of a novel coumarin derivative on the corrosion of mild steel in a hydrochloric acid solution, Chem. Cent. J., 2016, 10, 23. doi: 10.1186/s13065-0160170-3

82. T.A. Salman, Q.A. Jawad, M.A.M. Hussain, A.A. Al-Amiery, L.M. Shaker, A.A.H. Kadhum, M.S. Takriff and R.R. Hussain, New environmental friendly corrosion inhibitor of mild steel in hydrochloric acid solution: Adsorption and thermal studies, Cogent Eng., 2020, 7, no. 1, 1-17. doi: 10.1080/23311916.2020.1826077

83. A.A. Al-Amiery, Y.K. Al-Majedy, A.A.H. Kadhum and A.B. Mohamad, New coumarin derivative as an eco-friendly inhibitor of corrosion of mild steel in acid medium, Molecules, 2015, 20, no. 1, 366-383. doi: 10.3390/molecules20010366 
84. A. Al-Amiery, Coumarin-3-Amine as New Corrosion Inhibitor, Preprints, 2017, 2017070096. doi: 10.20944/preprints201707.0096.v1

85. G. Zhang and C.B. Musgrave, Comparison of DFT methods for molecular orbital eigenvalue calculations, J. Phys. Chem. A, 2007, 111, no. 8, 1554-1561. doi: $\underline{10.1021 / \mathrm{jp} 061633 \mathrm{o}}$

86. F.G. Hashim, T.A. Salman, S.B. Al-Baghdadi, T. Gaaz and A.A. Al-Amiery, Inhibition Effect of Hydrazine-Derived Coumarin on a Mild Steel Surface in Hydrochloric acid, Tribologia, 2020, 37, no. 3-4, 45-53. doi: $10.30678 / \mathrm{fjt} .95510$

87. A. Al-Amiery, New Corrosion Inhibitor Derived from Coumarin, Preprints, 2017, 2017080021. doi: 10.20944/preprints201708.0021.v1

88. D. Verma, S. Kaya, E. Ech-chihbi, F. El-Hajjaji, M. Phukan and H.M. Alnashiri, Investigations on some coumarin based corrosion inhibitors for mild steel in aqueous acid medium: Electrochemical, surface morphological, density functional theory and Monte Carlo simulation approach, J. Mol. Liq., 2021, 329, 115531. doi: 10.1016/j.molliq.2021.115531

89. S.R. Krishnamurthy and M.H.N. Parameswaran, Synergistic Effect of Iodide Ion and 4Hydroxy Coumarin on the Corrosion Inhibition of Mild Steel in Hydrochloric Acid, Int. Scholarly Res. Not., 2013, 184787, 1-6. doi: 10.1155/2013/184787

90. D.S. Zinad, M. Hanoon, R.D. Salim, S.I. Ibrahim, A.A. Al-Amiery, M.S. Takriff and A.A.H. Kadhum, A new synthesized coumarin-derived Schiff base as a corrosion inhibitor of mild steel surface in $\mathrm{HCl}$ medium: gravimetric and DFT studies, Int. J. Corros. Scale Inhib., 2020, 9, no. 1, 228-243. doi: 10.17675/2305-6894-2020-9-1-14

91. M. Yusoff, M. Azmi, M. Hussin, H. Osman, P. Raja, A. Abdul Rahim and K. Awang, An Electrochemical Evaluation of Synthesized Coumarin-Azo Dyes as Potential Corrosion Inhibitors for Mild Steel in $1 \mathrm{M} \mathrm{HCl}$ Medium, Int. J. Electrochem. Sci., 2020, 15, 11742-11756. doi: $10.20964 / 2020.12 .43$

92. G. Bereket, E. Hur, and C. Ogretir, Quantum chemical studies on some imidazole derivatives as corrosion inhibitors for iron in acid medium, J. Mol. Struct.: THEOCHEM, 2002, 578, 79-88. doi: 10.1016/S0166-1280(01)00684-4

93. J. Vosta and J. Eliasek, Study on corrosion inhibition from aspect of quantum chemistry, Corros. Sci., 1971, 11, 223-229. doi: 10.1016/S0010-938X(71)80137-3

94. E.E. Oguzie, Y. Li, S.G. Wang and F. Wanga, Understanding corrosion inhibition mechanisms-experimental and theoretical approach, $R S C A d v ., 2011,1,866-873$. doi: 10.1039/C1RA00148E

95. S. Xia, M. Qiu, L. Yu, F. Liu, and H. Zhao, Molecular dynamics and density functional theory study on relationship between structure of imidazoline derivatives and inhibition performance, Corros. Sci., 2008, 50, no. 7, 2021-2029. doi: 10.1016/j.corsci.2008.04.021

96. S.B. Al-Baghdadi, F.G. Hashim, A.Q. Salam, T.K. Abed, T.S. Gaaz, A.A. Al-Amiery, A.A.H. Kadhum, K.S. Reda and W.K. Ahmed, Synthesis and corrosion inhibition application of NATN on mild steel surface in acid media complemented with DFT studies, Results Phys., 2018, 8, 1178-1184. doi: 10.1016/j.rinp.2018.02.007 
97. F. Kandemirli and S. Sagdinc, Theoretical study of corrosion inhibition of amides and thiosemicarbazones, Corros. Sci., 2007, 49, no. 5, 2118-2130. doi: 10.1016/j.corsci.2006.10.026

98. C.D. Taylor, R.G. Kelly and M. Neurock, A first-principles analysis of the chemisorption of hydroxide on copper under electrochemical conditions: a probe of the electronic interactions that control chemisorption at the electrochemical interface, $J$. Electroanal. Chem., 2007, 607, no. 1-2, 167-174. doi: 10.1016/j.jelechem.2007.04.004

99. D. Wang, S. Li, Y. Ying, M. Wang, H. Xiao and Z. Che, Theoretical and experimental studies of structure and inhibition efficiency of imidazoline derivatives, Corros. Sci., 1999, 41, no. 10, 1911-1919. doi: 10.1016/S0010-938X(99)00027-X

100. J. Bartley, N. Huynh, S.E. Bottle, H. Flitt, T. Notoya and D.P. Schweinsberg, Computer simulation of the corrosion inhibition of copper in acid solution by alkyl esters of 5carboxybenzotriazole, Corros. Sci., 2003, 45, no. 1, 81-96. doi: 10.1016/S0010938X(02)00051-3

101. E.E. Oguzie, S.G. Wang, Y. Li and F.H. Wang, Influence of iron microstructure on corrosion inhibitor performance in acid media, J. Phys. Chem. C, 2009, 113, no. 19, 8420-8429. doi: 10.1021/jp9015257

102. M. Abd El-Raouf, E.A. Khamis, M.T.H. Abou and N.A. Negm, Electrochemical and quantum chemical evaluation of new bis(coumarins) derivatives as corrosion inhibitors for carbon steel corrosion in $0.5 \mathrm{M} \mathrm{H}_{2} \mathrm{SO}_{4}$, J. Mol. Liq., 2018, 225, 341-353. doi: 10.1016/j.molliq.2018.01.148

103. V. Udowo, Computational Studies of the Corrosion Inhibition Potentials of Quercetin and Coumarin, Arch. Org. Inorg. Chem. Sci., doi: 10.32474/AOICS.2018.02.000133 